\title{
Pollen DNA metabarcoding and related methods in global change ecology: prospects, challenges, and progress
}

\author{
Karen Bell ${ }^{1}$, Katherine Turo ${ }^{2}$, Abigail Lowe ${ }^{3}$, Kevin Nota ${ }^{4}$, Alexander Keller ${ }^{5}$, Francisco \\ Encinas-Viso ${ }^{6}$, Laura Parducci ${ }^{7}$, Rodney Richardson ${ }^{8}$, Richard Leggett ${ }^{9}$, Berry Brosi ${ }^{10}$, \\ Kevin Burgess ${ }^{11}$, Yoshihisa Suyama ${ }^{12}$, and Natasha de Vere ${ }^{13}$ \\ ${ }^{1}$ University of Western Australia \\ ${ }^{2}$ Rutgers The State University of New Jersey \\ ${ }^{3}$ National Botanic Garden of Wales \\ ${ }^{4}$ Uppsala universitet Evolutionsbiologiskt centrum \\ ${ }^{5}$ Ludwig-Maximilians-Universität München \\ ${ }^{6} \mathrm{CSIRO}$ \\ ${ }^{7}$ Uppsala University \\ ${ }^{8}$ University of Maryland Center for Environmental Science \\ ${ }^{9}$ Earlham Institute \\ ${ }^{10}$ Emory University \\ ${ }^{11}$ Affiliation not available \\ ${ }^{12}$ Tohoku University \\ ${ }^{13}$ University of Copenhagen
}

January 29, 2022

\begin{abstract}
Anthropogenic activities are leading to changes in the environment at global scales, and understanding these changes requires rapid, high-throughput methods of assessment. Pollen DNA metabarcoding and related methods provide advantages in throughput and efficiency over traditional methods, such as microscopic identification of pollen and visual observation of plant-pollinator interactions. Pollen DNA metabarcoding is currently being applied to assessments of plant-pollinator interactions and their responses to land-use change such as increased agricultural intensity and urbanisation, surveillance of ecosystem change, and monitoring of spatiotemporal distribution of allergenic pollen. In combination with historical specimens, pollen DNA metabarcoding can compare contemporary and past ecosystems. Current technical challenges with pollen DNA metabarcoding include the need to understand the relationship between sequence read and species abundance, develop methods for determining confidence limits for detection and taxonomic classification, increase method standardisation, and improve of gaps in reference databases. Future research expanding the method to intraspecific identification, analysis of DNA in ancient pollen samples, and increased use of museum and herbarium specimens could open further avenues for research. Ongoing developments in sequencing technologies can accelerate progress towards these goals. Global ecological change is happening rapidly, and we anticipate that high-throughput methods such as pollen DNA metabarcoding are critical for assessing these changes and providing timely management recommendations to preserve biodiversity and the evolutionary and ecological processes that support it.
\end{abstract}

Manuscript type: Special Issue

Pollen DNA metabarcoding and related methods in global change ecology: prospects, challenges, and progress 
Karen L. Bell ${ }^{1, \mathrm{a}}$, Katherine J. Turo ${ }^{2}$, Abigail Lowe ${ }^{3, \mathrm{~b}}$, Kevin Nota ${ }^{4, \mathrm{~b}}$, Alexander Keller ${ }^{5, \mathrm{~b}}$, Francisco EncinasViso $^{6, b}$, Laura Parducci ${ }^{3,7, b}$, Rodney Richardson ${ }^{8, b}$, Richard M. Leggett ${ }^{9}$, Berry J. Brosi ${ }^{10}$, Kevin S. Burgess $^{11}$, Yoshihisa Suyama ${ }^{12}$, Natasha de Vere ${ }^{13}$

${ }^{1}$ CSIRO Health \& Biosecurity and CSIRO Land \& Water, 147 Underwood Avenue, Floreat, WA, Australia; School of Biological Sciences, University of Western Australia, Crawley, WA 6009, Australia.

${ }^{2}$ Department of Ecology, Evolution, and Natural Resources, Rutgers University, New Brunswick, NJ, 08901, United States.

${ }^{3}$ National Botanic Garden of Wales, Llanarthne, United Kingdom.

${ }^{4}$ Department of Ecology and Genetics, Evolutionary Biology Centre, Uppsala University, Norbyvägen 18D, 75236 Uppsala, Sweden.

${ }^{5}$ Organismic and Cellular Interactions, Biocenter, Ludwig-Maximilians-Universität München, Großhaderner Str. 2, 82152 Planegg, Germany.

${ }^{6}$ Centre for Australian National Biodiversity Research, CSIRO, Black Mountain, ACT, Australia

${ }^{7}$ Department of Environmental Biology, Sapienza University of Rome, Rome, Piazzale Aldo Moro 5, 00185, Italy.

8 Appalachian Laboratory, University of Maryland Center for Environmental Science, 301 Braddock Road, Frostburg, MD 21532, United States.

${ }^{9}$ Earlham Institute, Norwich Research Park, Norwich, Norfolk, NR4 7UZ, United Kingdom.

${ }^{10}$ Department of Biology, University of Washington, USA

${ }^{11}$ Department of Biology, College of Letters and Sciences, Columbus State University, University System of Georgia, United States.

12 Field Science Center, Graduate School of Agricultural Science, Tohoku University, 232-3 Yomogida, Naruko-onsen, Osaki, Miyagi 989-6711, JAPAN

${ }^{13}$ Natural History Museum of Denmark, University of Copenhagen, Denmark

a Corresponding author: karen.bell@csiro.au

b Authors AL, KN, AK, FEV, LP, and RR all contributed equally.

ORCID:

KLB: 0000-0002-4445-4026

KJT: 0000-0003-1578-4592

AL: 0000-0001-5431-8936

KN: 0000-0002-4744-5205

AK: 0000-0001-5716-3634

FEV: 0000-0003-0426-2342

LP: 0000-0003-1956-4757

LP: 0000-0003-1956-4757

YS: 0000-0002-3136-5489

NdV: 0000-0001-9593-6925

Short running title: Pollen metabarcoding in global change ecology 


\section{Abstract}

Anthropogenic activities are leading to changes in the environment at global scales, and understanding these changes requires rapid, high-throughput methods of assessment. Pollen DNA metabarcoding and related methods provide advantages in throughput and efficiency over traditional methods, such as microscopic identification of pollen and visual observation of plant-pollinator interactions. Pollen DNA metabarcoding is currently being applied to assessments of plant-pollinator interactions and their responses to land-use change such as increased agricultural intensity and urbanisation, surveillance of ecosystem change, and monitoring of spatiotemporal distribution of allergenic pollen. In combination with historical specimens, pollen DNA metabarcoding can compare contemporary and past ecosystems. Current technical challenges with pollen DNA metabarcoding include the need to understand the relationship between sequence read and species abundance, develop methods for determining confidence limits for detection and taxonomic classification, increase method standardisation, and improve of gaps in reference databases. Future research expanding the method to intraspecific identification, analysis of DNA in ancient pollen samples, and increased use of museum and herbarium specimens could open further avenues for research. Ongoing developments in sequencing technologies can accelerate progress towards these goals. Global ecological change is happening rapidly, and we anticipate that high-throughput methods such as pollen DNA metabarcoding are critical for assessing these changes and providing timely management recommendations to preserve biodiversity and the evolutionary and ecological processes that support it.

Keywords: pollen; pollination; DNA metabarcoding; metagenomics; environmental DNA; global change ecology; ecosystem change

\section{Introduction}

Anthropogenic activities are leading to global changes in the environment, including, habitat loss (Ellis, Klein Goldewijk, Siebert, Lightman, \& Ramankutty, 2010), climate change (Hansen, Reudy, Sato, \& Lo, 2010), biodiversity decline (e.g., Bowler et al., 2020; Butchart et al., 2010), and the spread of invasive species and diseases (Hulme, 2009; Pyšek et al., 2020). Such global changes can act additively or interactively (Didham, Tylianakis, Gemmell, Rand, \& Ewers, 2007; Peters et al., 2019) to alter species composition through events such as local introductions and extinctions (Mathiasson \& Rehan, 2020; Portman, Tepedino, Tripodi, Szalanski, \& Durham, 2018), shifts in phenology (Bartomeus et al., 2011; Forrest, 2015), and changes in the dispersal and connectivity of populations (Damschen et al., 2019). These impacts can subsequently affect the spatiotemporal overlap of species and their behaviour, which can alter species interactions, restructure food webs (Dunn et al., 2018; Kortsch, Primicerio, Fossheim, Dolgov, \& Aschan, 2015; Richardson et al., 2021), and create network instability (Brosi \& Briggs, 2013; Revilla, Encinas-Viso, \& Loreau, 2015). Ultimately, these changes can lead to negative impacts on ecosystem services (e.g., pollination; Burkle, Marlin, \& Knight, 2013; Potts et al., 2010), economic productivity (e.g., decreasing agricultural production; Lark, Spawn, Bougie, \& Gibbs, 2020; Reilly et al., 2020) and human health and quality of life (e.g., changing distribution and phenology of allergenic pollen; Anderegg et al., 2021; or loss of pollinator-dependent crops; M. R. Smith, Singh, Mozaffarian, \& Myers, 2015). Understanding and managing these changes requires rapid, high-throughput assessments and responses.

Pollen is a powerful biomarker for detecting spatial and temporal variation in species assemblages and interspecific interactions, making it ideal for a high-throughput assessment of global ecological change (Hornick et al., 2021). For example, the presence of pollen in environmental samples can be used to determine plant species composition, which can be helpful for surveying changes in biodiversity (Leontidou et al., 2021; Matthias et al., 2015), comparing current ecosystems to historical samples (Gous, Swanevelder, Eardley, \& Willows-Munro, 2019; Simanonok et al., 2021), the early detection of biological invasions (Tremblay et al., 2019), and monitoring airborne allergenic pollen impacting human health (Suanno, Aloisi, FernándezGonzález, \& Del Duca, 2021). Pollen can also be used to assess changes in phenology (Burkle et al., 2013), detect plant-pollinator interactions (Bänsch et al., 2020; Gresty et al., 2018; Kaluza et al., 2017; Lucas, 
Bodger, Brosi, Ford, Forman, Greig, Hegarty, Jones, et al., 2018; Richardson et al., 2021; Sponsler, Shump, Richardson, \& Grozinger, 2020), reconstruct pollen transport networks (Tur, Vigalondo, Trojelsgaard, Olesen, \& Traveset, 2014), and reconstruct past vegetation and, from this, climate (Courtin et al., 2021; Liu et al., 2021; Niemeyer, Epp, Stoof-Leichsenring, Pestryakova, \& Herzschuh, 2017; Laura Parducci et al., 2019). The identification of pollen from the bodies of animals is particularly useful for the reconstruction of plantpollinator interaction networks because it increases the temporal scale of information obtained, leading to more connected networks than those reconstructed through observations of flower visitation (Arstingstall et al., 2021; Bosch, Gonzalez, Rodrigo, \& Navarro, 2009; de Manincor et al., 2020).

Traditionally, taxonomic identification of pollen is based on the visual observation of pollen morphology. Pollen grains are stained and mounted on microscope slides and identified to the lowest possible taxonomic group using morphological characteristics visualised with light microscopy. While counting pollen with this method is possible and can be used to assign species abundance, it requires highly trained specialists (of whom there is a small and dwindling number) and is time-consuming, leading to most identifications taking place on small subsets of pollen samples (Stillman \& Flenley, 1996). Moreover, the lack of variation in distinctive morphological characteristics limits the microscopic identification of pollen typically to the level of genus and often only family (Lau et al., 2019; Mander \& Punyasena, 2014; Richardson et al., 2018). Automated taxonomic identification has been suggested (Stillman \& Flenley, 1996) and implemented to overcome these limitations in three ways. First, image analysis of morphological characteristics employs methods such as texture analysis (Marcos et al., 2015), and multiple convolutional neural networks (Bourel et al., 2020; Olsson et al., 2021; M. Polling et al., 2021; Sevillano, Holt, \& Aznarte, 2020). Second, methods based on chemical characteristics include Raman spectroscopy (Pereira, Guedes, Abreu, \& Ribeiro, 2021), magnetic resonance spectroscopy (MRS) (Klimczak, Ebner von Eschenbach, Thompson, Buters, \& Meuller, 2020), or Fourier-transform infrared (FTIR) spectroscopy (Muthreich, Zimmermann, Birks, Vila-Vicosa, \& Seddon, 2020; Zimmermann, 2018). Spectroscopy has been applied to single pollen grains (Diehn et al., 2020) and, as far as we know, it has not been used for mixed-species pollen samples and may be limited in this capacity. Machine learning (Goncalves et al., 2016) or deep learning (Dunker et al., 2021) methods can be used to improve the identification of taxa from the data obtained with either morphological or chemical methods. In addition, flow cytometry has been successfully used to count pollen and sort grains for downstream analyses (Kron, Loureiro, Castro, \& Čertner, 2021). Combining chemical and image analyses with flow cytometry and deep learning methods can yield fast and accurate taxon identification and quantification (Dunker et al., 2021). However, although these methods work in some contexts, only a small number of different pollen types are often included, and most studies have not tested multi-species pollen samples. Moreover, most advanced techniques require specialised equipment and extensive training datasets to calibrate the taxonomic assignments. Research on a third method for pollen identification, molecular genetics (i.e., the use of DNA sequences), has recently gained attention for its high-throughput capabilities and ubiquitous techniques and equipment and is the focus of this paper.

The DNA present in the cells of pollen can be used for the taxonomic identification of plant species by using standard DNA barcoding (for identifying a single-species sample), metabarcoding (mixed-species samples), or single-pollen genotyping (direct amplification and sequencing of individual pollen grains; Isagi \& Suyama, 2011). Standard DNA barcoding approaches for plants typically use chloroplast DNA (cpDNA; e.g., rbc L, mat K, trn L; CBOL Plant Working Group et al., 2009) and/or nuclear ribosomal DNA (e.g., ITS1, ITS2; Chen et al., 2010). This approach has been extended to the identification of pollen, where DNA metabarcoding and high-throughput sequencing (HTS) are used to sequence PCR-amplified DNA of all the species in a mixed-species pollen sample (Bell et al., 2016; Cristescu, 2014; Taberlet, Coissac, Pompanon, Brochmann, \& Willerslev, 2012). This approach can be applied in any standard molecular laboratory (assuming PCR product is subsequently sent off for HTS sequencing) and has been used extensively on bulk pollen extract for detecting plant-pollinator interactions through freshly collected pollinator specimens (e.g., Keller et al., 2015; Lucas et al., 2018) and museum specimens (e.g., Gous et al., 2019), identifying the floral composition of honey (e.g., Hawkins et al., 2015), and monitoring allergenic pollen (e.g., Kraaijeveld et al., 2015). 
Compared to morphology-based identifications, DNA-based identifications of pollen provide several advantages: there are more people with the required laboratory and bioinformatics expertise; greater taxonomic resolution can be obtained (Lau et al., 2019); there is potential for higher throughput (Sickel et al., 2015); and it is possible to identify the entire pollen composition of a sample (e.g., pollen load carried by an individual pollinator), rather than being limited to a subsample that is tractable by microscopic identification. DNA metabarcoding still has some challenges, mainly in respect to assigning abundances (Bell et al., 2019) and species resolution, which depends on the gene region used for metabarcoding and the quality and completeness of the relevant reference database (Jones, Twyford, et al., 2021). In most cases, however, pollen DNA metabarcoding resolves taxonomy equally well or better than traditional morphological based methods (Keller et al., 2015; Leontidou et al., 2018; Macgregor et al., 2019). Pollen DNA metabarcoding data is generally considered to be semi-quantitative (i.e., sequence read counts are correlated with pollen grain numbers in a sample) (Baksay et al., 2020; Hawkins et al., 2015; Alexander Keller et al., 2015; Kraaijeveld et al., 2014; Marcel Polling et al., 2022; Richardson et al., 2018; Richardson et al., 2021), particularly for the most abundant taxa in a sample (Bänsch et al., 2020), however, quantification is dependent on factors such as study system and choice of gene region, as well as laboratory and bioinformatic methods (Berry, Mahfoudh, Wagner, \& Loy, 2011; O’Donnell, Kelly, Lowell, \& Port, 2016; Piñol, Senar, \& Symondson, 2019; Richardson et al., 2018; Richardson et al., 2015). Ongoing method development in pollen DNA metabarcoding is likely to improve taxonomic resolution and quantification accuracy, and could eventually include intraspecific identifications (i.e., distinct subspecies or populations within a species). These developments could include using more of the genome (Bell, Petit, et al., 2021; Lang, Tang, Hu, \& Zhou, 2019), using longer reads (Peel et al., 2019), and correcting for copy number of barcode gene regions (L. Garrido-Sanz, Senar, \& Pinol, 2021).

While methods for pollen DNA metabarcoding are still evolving, it is evident that a molecular approach to pollen identification represents an important tool for understanding and monitoring ecosystems under global change. This paper will review the history of pollen DNA metabarcoding and related methods, discuss current applications of these methods, outline the basic requirements for a DNA-based pollen identification study, and provide a current assessment of progress on technical issues and future research directions.

History of pollen DNA metabarcoding

Research identifying species or genotypes of plants using DNA from pollen began in the 1990s and was based on Sanger sequencing of individual pollen grains. Given that conifers typically have male inheritance of plastids, early studies indicated that it should be easier to genotype conifer pollen using the 'standard' DNA barcoding gene regions ( $r b c \mathrm{~L}$ and mat K; CBOL Plant Working Group et al., 2009) given that they are on the plastid genome. However, in most angiosperm species, plastids are typically inherited maternally, and plastid DNA is less abundant after pollen maturation (Nagata, 1996). Thus, in the early days of pollen barcoding, researchers expected this method to work effectively on gymnosperm pollen, but not necessarily on angiosperm pollen. Suyama et al. (1996) were the first to amplify and sequence cpDNA of Abies (fir, a gymnosperm) pollen collected from Quaternary peat at Kurota Lowland, Fukui, Japan. Petersen, Johansen, and Seberg (1996) were the first to amplify short regions of cpDNA from single pollen grains of angiosperms (Hordeum and Secalegrasses). The technique of Suyama et al. (1996) was later used to analyse cpDNA from ancient pollen of conifers (Pinus sylvestris; L. Parducci, Suyama, Lascoux, \& Bennett, 2005) and angiosperms (Fagus orientalis ; Paffetti et al., 2007) extracted from ancient sediments, Pinus pollen grains collected from a glacier (Nakazawa et al., 2013), and airborne pollen grains of Pinus (Ito, Suyama, Ohsawa, \& Watano, 2008).

Today, we know cpDNA is present in angiosperm pollen since cpDNA gene regions (e.g., $r b c \mathrm{~L}$, trn L) have been successfully amplified from single pollen grains and bulk pollen samples in many studies. Single-pollen genotyping (MATSUKI, ISAGI, \& SUYAMA, 2007; Suyama, 2011) remains labour intensive and a challenge for the research community. However, Isagi and Suyama (2011) have successfully used multiplex PCR and a single-pollen genotyping method on fresh pollen to conduct paternity analysis and to infer the pattern and distance of pollen dispersal in modern plant populations. The same technique was successively used in several studies by their groups (Hasegawa, Suyama, \& Seiwa, 2009; Hirota et al., 2013; MATSUKI et al., 
2007; Matsuki, Tateno, Shibata, \& Isagi, 2008). Sanger sequencing has also been used with the cloning of PCR products (amplicons) to identify pollen from bulk samples (Bruni et al., 2015; Galimberti et al., 2014).

With the advent of HTS technology, DNA-based pollen identification is no longer dependent on the timeconsuming isolation and sequencing of individual pollen grains (Aziz \& Sauve, 2008; MATSUKI et al., 2007) or the cloning of amplicons prior to Sanger sequencing (Bruni et al., 2015; Galimberti et al., 2014). Instead, with HTS, researchers have been able to sequence pollen from bulk samples using DNA metabarcoding. This breakthrough has allowed for rapid, large-scale species identification of species within mixtures. Early proofof-concept papers on pollen DNA metabarcoding demonstrated the feasibility of the method (e.g., Cornman et al., 2015; Hawkins et al., 2015; Alexander Keller et al., 2015; Kraaijeveld et al., 2014; Richardson et al., 2015) and it has since been applied to a range of applications. These include understanding the foraging behaviour of honeybees (e.g., Jones, Brennan, et al., 2021; Alexander Keller et al., 2015; Richardson et al., 2021; Richardson et al., 2015) and other pollinators (e.g., Bell, Batchelor, et al., 2021; Kratschmer, Petrović, Curto, Meimberg, \& Pachinger, 2020; Lucas, Bodger, Brosi, Ford, Forman, Greig, Hegarty, Neyland, et al., 2018; MacGregor et al., 2019), examining historical flower visitation (Gous et al., 2019; Simanonok et al., 2021), monitoring allergenic pollen (Brennan et al., 2019; Kraaijeveld et al., 2014), biodiversity assessments (Leontidou et al., 2021; Johnson et al. 2021), determining the floral origin of honey (Hawkins et al., 2015; Milla et al., 2021; Khansaritoreh et al., 2020), and monitoring invasive species (Tremblay et al., 2019).

Advances and cost reductions in HTS and the advent of third generation sequencing technologies may further improve pollen-based DNA identifications. As the costs of HTS decrease, researchers are moving from traditional DNA metabarcoding, based only on a small number of gene regions, to metagenomics, which is based on whole genomes or reduced-representation genomes. Methods based on whole-genome shotgun sequencing of pollen mixtures, either using the plastid reads only (Lang et al., 2019) or all reads (Bell, Petit, et al., 2021), have shown improved taxonomic resolution and quantification over DNA metabarcoding, but still require the presence of suitable reference databases for identification. This is discussed in more detail in section 5 .

Current and potential applications of pollen DNA metabarcoding and related methods in global change ecology

Since the early pollen DNA metabarcoding papers, several papers have published methodological improvements and proof-of-concept for a range of sample types. More recently, these methods have begun to be applied to ecological questions, including papers addressing questions related to global ecological change. To assess the current application of pollen DNA metabarcoding to questions of global change, we completed a Web of Science search (accessed 11/30/2021) with the terms: "pollen" and "metabarcoding" or "pollen" and "meta-barcoding". From a list of 134 results, we excluded irrelevant papers, reviews, and those papers which focused solely on methods development. We also added several papers $(n=28)$ to this list based on previous knowledge. Following these alterations, we examined a reduced list of 80 papers from 2014-2021 (Supplementary Table S1). Generally, we found increasing numbers of papers with time, and a shift in 2017 from predominantly proof-of-concept papers to those exclusively focused on answering an ecological question of interest (Figure 1). Research to date has been concentrated on pollinator foraging behaviour, with an early focus on honeybee foraging, likely due to the ease with which mass amounts of pollen can be collected from hives with pollen traps or from honey samples. However, applications of pollen DNA metabarcoding are varied and address, among many other topics, lepidopteran migration, historic foraging reconstruction, and airborne pollen monitoring.

Many applications of pollen DNA metabarcoding that address ecological change take advantage of the improved resolution and efficiency that these methods can provide. One specific area of ecological research is in the reconstruction of plant-pollinator interaction networks from the pollinator perspective. An important consideration when creating plant-pollinator interaction networks is the perspective that a given methodology provides. Historically, visitation networks have been plant-focused, with pollinators counted or collected from selected flowers. These observations can provide a complete interaction network for the flowers and are thus a good representation of pollinator visitation. However, such observations incompletely represent the 
dietary intake of the flower-visiting animal (Arstingstall et al., 2021; Popic, Wardle, \& Davila, 2013). On the other hand, pollen-based methods, such as DNA metabarcoding or light microscopy, provide the animal perspective and allow exploration of the dietary input obtained from these interactions (Piko et al., 2021; Pornon, Andalo, Burrus, \& Escaravage, 2017; Zhao et al., 2018). Pollen-based methods may also enable the assessment of plant-pollinator networks in hard-to-observe places, thus avoiding sampling biases. For example, observation-based detections are impractical in the forest canopy, but pollen analyses can capture bee foraging patterns (C. Smith, Weinman, Gibbs, \& Winfree, 2019).

Another advantage of pollen-based methods, and an essential factor to be considered in the study design, is the scalability of the samples that can be used to infer and contrast preferences of individual foragers (Casanelles-Abella et al., 2021; Elliott et al., 2020; Piko et al., 2021), and hive, colony, nest or species level assessments (Danner, Keller, Härtel, \& Steffan-Dewenter, 2017; Nürnberger, Keller, Härtel, \& Steffan-Dewenter, 2019; Sickel et al., 2015). Individual-level assessments allow researchers to address potential intraspecific variation by having snapshots of foraging and immediate responses to spatiotemporal or anthropogenic changes (Piko et al., 2021). Longer-term samples provide comprehensive insights into the complete foraging spectrum and species' dietary niche, co-evolution and long-term responses to changes (Kaluza et al., 2017; Vaudo, Biddinger, Sickel, Keller, \& Lopez-Uribe, 2020; Wilson et al., 2021). Resource partitioning and specialisation can be analysed throughout the entire network from the community to the individual (Brosi, 2016; Elliott et al., 2020; Lucas, Bodger, Brosi, Ford, Forman, Greig, Hegarty, Jones, et al., 2018). In addition, historical samples can be used as an input (e.g., from museum specimens or honey samples), which allows a direct comparison of foraging changes through extended time periods (Gous et al., 2019; Jones, Brennan, et al., 2021).

This "animal perspective" also directly links to the functional and nutritional components of pollen provided to animals and their offspring and can thus, for example, be used to relate impacts of changes in plant resource diversity to nutritional needs, development, and health (Donkersley et al., 2017; Trinkl et al., 2020). Recently, the importance of transmitting microbes between plants and pollinators by hitchhiking pollen grains, nectar and animal bodies have been implied (A. Keller et al., 2021; McFrederick \& Rehan, 2016; Zemenick, Vannette, \& Rosenheim, 2021). This accounts both for microbes with beneficial (Dharampal, Carlson, Currie, \& Steffan, 2019; Vuong \& McFrederick, 2019) and detrimental (A. Keller et al., 2018; Voulgari-Kokota, Steffan-Dewenter, \& Keller, 2020) effects on host ecology, nutrition and health (Engel et al., 2016; Vannette, 2020; Voulgari-Kokota, Grimmer, Steffan-Dewenter, \& Keller, 2018). Given these advantages of pollen-based networks and the high-throughput capabilities of genetic methods, a wide range of broad and fine-scale ecological questions may be answered. Particularly urgent are studies investigating how interactions change throughout space (across land-use gradients, resource availability) and time (shortterm, e.g., seasonal, or long-term via the use of historical museum specimens) and elucidating consequences that accompany climate change and habitat disruption and other anthropogenic influences.

Understanding pollinator responses to land-use change

In recent decades, there have been broad scale shifts in land use with subsequent changes in resource availability to pollinators. Overall, there has been deforestation in the tropics but widespread reforestation and afforestation in temperate regions, often with monocultures or small numbers of tree species (Song et al., 2018). In the US, there has been considerable reforestation and urbanisation (He et al., 2019; Song et al., 2018), at the expense of grassland and herbaceous areas (Lark, Meghan Salmon, \& Gibbs, 2015; Otto, Roth, Carlson, \& Smart, 2016). Pollen DNA metabarcoding has been used to understand the flexibility of pollinator species dietary niche in response to such changing environmental conditions (Vaudo et al., 2020) and to evaluate and improve conservation efforts (Gresty et al., 2018; Piko et al., 2021). Land-use change can also alter the diversity of resources available to pollinators, with decreased floral richness in agricultural monocultures and context-specific increases or decreases with urbanisation (da Rocha-Filho et al., 2021; Jones, Brennan, et al., 2021; Lucek et al., 2019; Richardson et al., 2021; Samuelson, Gill, \& Leadbeater, 2020). Pollen DNA metabarcoding has been used to understand the response of pollinators to resource-rich and resource-poor environments (Casanelles-Abella et al., 2021; Danner et al., 2017; Kaluza et al., 2017; 
Sponsler et al., 2020; Wilson et al., 2021) and to understand the link between behaviour and pollen intake in resource-poor environments (Nurnberger et al., 2019).

Expansions in agricultural land cover can have a range of impacts on pollinators (Potts et al., 2010), including decreasing floral resource diversity (Grab et al., 2019; Richardson et al., 2021), increasing pesticide exposure risk (Douglas, Sponsler, Lonsdorf, \& Grozinger, 2020; Douglas \& Tooker, 2015), and increased parasite loads (Cohen et al., 2021). Pollen DNA metabarcoding can show how pollinators respond to this changing agroecosystem and can be used to monitor changes. For instance, a comparison of modern-day honey with samples collected 65 years prior demonstrated shifts in honeybee forage composition and a reduction in white clover, Trifolium repens (Jones, Brennan, et al., 2021). Recent studies, using both molecular and morphological pollen identification, have also found that honeybees situated in modern agricultural landscapes tend to collect a lower diversity of forage relative to nearby non-agricultural landscapes (Richardson et al., 2021; Samuelson et al., 2020). To date it is unclear how this variation in forage diversity corresponds to pollinator health. Pollinator diets can also be affected through the uptake of agricultural environmental schemes (AES) in which supplemental planting can improve forage availability for pollinators on farms. Molecular analysis of bee collected pollen can help evaluate if conservation plantings are successfully supporting bee populations and identify which resources bees forage on (Gresty et al. 2018; McMinn-Sauder, 2020). Overall, this research demonstrates how pollinators can be used to monitor changes associated with agricultural land use and that there is a need for continued study. Future research efforts in this area will require greater spatial replication and comparisons to a wider diversity of alternate landscape types, two challenges to which molecular identification of pollen is uniquely suited.

While both agricultural and urban intensification can negatively impact pollinator communities through habitat loss (Potts et al., 2010), many urban environments also support rich pollinator diversity (Baldock et al., 2015; Hall et al., 2017), especially when landscapes exhibit moderate or intermediate levels of urbanisation (Wenzel, Grass, Belavadi, \& Tscharntke, 2020). In part, pollinators can thrive in cities due to the intensive cultivation of flowering resources (Baldock et al., 2015; Sponsler et al., 2020) and spontaneous urban vegetation (i.e., weeds) (Lowenstein, Matteson, \& Minor, 2018; Turo \& Gardiner, 2019). However, cities also filter pollinator communities and select for specific traits such as cavity-nesting and generalist foraging (Wenzel et al., 2020). Recent studies have focused on the management and improvement of urban green spaces (e.g., gardens, vacant lots, road verges, green roofs) to increase the diversity of urban pollinators, particularly for rare and threatened bee species (Threlfall et al., 2015; Turo \& Gardiner, 2019). Improved characterisation of urban foraging networks can inform green space development. However, traditional methods for monitoring plant-pollinator interactions (e.g., flower-visitor observations, hand-netting) can be challenging to use in urban areas due to restrictions on sampling private property and the high floral diversity present in the urban matrix (Sponsler et al., 2020). Recently, pollen DNA metabarcoding has been used to characterise plant-pollinator interactions and pollinator diets in urban environments (CasanellesAbella et al., 2021; Potter et al., 2019; Sponsler et al., 2020). The findings of this research suggest that pollen DNA metabarcoding can be a useful tool to investigate how urban insect pollinators partition their diet from available floral resources (especially native and non-native forage). Pollen DNA metabarcoding can also evaluate how urban habitat plantings influence bee foraging and subsequent population growth (Potter et al., 2019).

Monitoring and surveillance of ecosystem change

Identifying plant biodiversity from pollen provides a valuable tool for surveillance of changes in the ecosystem, which has been applied to the early detection of invasive species and diseases (Tremblay et al., 2019), and could potentially be used for monitoring for the presence of rare, threatened, or endangered species. Community-level monitoring of plant biodiversity through pollen DNA metabarcoding could track changes in species composition, range, and phenology, providing a high-throughput alternative to botanical surveys (Johnson et al., 2021; Leontidou et al., 2021; Milla, Bovill, Schmidt-Lebuhn, \& Encinas-Viso, in press). These studies could be particularly beneficial when combined with other high-throughput methods like remote sensing or unmanned aerial vehicle surveys (Ancin-Murguzur, Munoz, Monz, \& Hausner, 2020). There is 
potential for pollen-based monitoring to be closely linked to management, with unexpected detections or non-detections to trigger a management response. Methods that would enable this technology need to be developed to provide probabilistic confidence estimates for identifications and avoid false positives triggering unnecessary management responses. The development of methods for the surveillance of aquatic invasive species via eDNA has been discussed (Darling, Pochon, Abbott, Inglis, \& Zaiko, 2020; Sepulveda, Nelson, Jerde, \& Luikart, 2020), and the same issues would apply to pollen-based surveillance methods.

\section{Comparison to past ecosystems}

The ability to assess global ecological change often relies on the comparison of contemporary data to historical data. Pollen identification is potentially a particularly useful tool for studying ecological change based on its presence on historical animal specimens and its preservation in ancient sediments. This type of sampling enables the comparison of contemporary to past ecosystems and establishes more accurate baselines for conservation. Preserved pollinating insects in museum collections often have pollen on their bodies or corbiculae, and these pollen grains can be identified through DNA metabarcoding to provide information on historical insect foraging patterns (Gous et al., 2019). For example, pollen DNA metabarcoding of a century of foraging by the endangered rusty patched bumble bee found that decline was unlikely to be driven by changes in forage (Simanonok et al., 2021). Similar studies are expected to give insights on the past foraging behaviour of other pollinating species and inform processes associated with more recent declines.

Pollen preservation in ancient sediments, in combination with ancient sedimentary DNA (Capo et al., 2021), also provides a resource for understanding past ecosystems. Usually, the pollen grains are examined morphologically, while the sediments are analysed through DNA sequencing to provide complementary data sources (Liu et al., 2021; Laura Parducci et al., 2017). This approach has been used to determine conservation baselines for offshore islands in New Zealand (Wilmshurst et al., 2014). Pollen retrieved from lake sediments is theoretically an ideal material for ancient DNA analyses in both conifers and angiosperms: depositional conditions are fast and reduce physical damage of the grains; burial is rapid, reducing the exposure of the grains to biotic degradation (L. Parducci, Nota, \& Wood, 2019). By accessing the DNA in ancient pollen, there is potential for further information to be obtained on past ecosystems (Niemeyer et al., 2017). This is an area where further method development could prove useful (see section 5).

Monitoring impacts on human health

Changes in pollen abundance and distribution due to climate change will likely have severe impacts on human health (Anderegg et al., 2021; Kurganskiy et al., 2021). Airborne pollen sampling, combined with DNA metabarcoding, allows allergenic species to be monitored across large spatiotemporal scales (Brennan et al., 2019; Leontidou et al., 2018) and can identify seasonal changes in allergenic species (Campbell et al., 2020; Uetake et al., 2021). Many plant families with highly allergenic pollen are difficult to identify through pollen morphology, however, the increased taxonomic resolution provided by DNA metabarcoding can allow allergenic species to be distinguished from non-allergenic species (e.g., Poaceae; Brennan et al., 2019; Urticaceae; Marcel Polling et al., 2022). The relationship between the presence of specific pollen types and human health responses can be investigated to identify the most harmful species (Rowney et al., 2021). Airborne pollen monitoring has been occurring for many years, and successful amplification of DNA from historical microscope slides shows the potential to monitor long-term ecological changes (Marcel Polling et al., 2022).

Box 1: Designing a study using pollen DNA metabarcoding and related methods

There is a broad range of applications for pollen DNA metabarcoding and related methods. The experimental design will depend on the questions being addressed in the study and the time, budget, and skillsets available. There are four main steps in identifying plant species from pollen: (1) obtaining the pollen sample; (2) selecting appropriate gene region(s) and creating a reference database; (3) isolating and sequencing DNA; (4) bioinformatic analysis to compare sequencing reads to reference databases (Fig. 2). These four steps are outlined below. 


\section{Step 1: Obtaining the pollen sample}

Pollen can be obtained from a range of environmental samples. Most often it is sampled from insects, either directly from the body (Chang et al., 2018; Pornon et al., 2016; Suchan, Talavera, Saez, Ronikier, \& Vila, 2019), or through provisions in nests (Gresty et al., 2018; McFrederick \& Rehan, 2016), honey (de Vere et al., 2017; Jones, Brennan, et al., 2021), or honeycomb (Tanaka, Nozaki, Nakadai, Shiwa, \& Shimizu-Kadota, 2020). Alternatively, pollen may be sampled from the air (Brennan et al., 2019; Leontidou et al., 2018). How, where, and when a sample is collected affects the number and diversity of target species sampled and the plant richness and diversity captured. For example, when sampling directly from a pollinator's body, researchers should consider the influence of body size and the pilosity of insects on the number and diversity of pollen retained (Cullen et al., 2021). Likewise, capturing foraging insects by hand-netting may be limited by surveyor bias. Some sampling methods are specific to particular taxonomic groups (e.g., honey sampling or pollen trapping; Judd, Huntzinger, Ramirez, \& Strange, 2020). The temporal scale of a pollen sample should also be considered. Pollen from an individual represents a single foraging trip, whilst pollen trapping usually entails pooling samples so multiple trips from multiple bees can be sampled over a short period. Pollen provisions in solitary bee nests represent multiple trips by one individual. The temporal scale of airborne samplers is dependent on study design. The sampling period defines the knowledge which can be gained (e.g., sampling pollen from social bees with a long flight period during one month of the year does not give a global picture of resource use). The sampling period should also consider floral phenology, as pollen will only be present when the plants are in flower.

The quantity of pollen required for the selected sequencing method, and the quantity of pollen available per sample will determine whether samples need to be pooled. Pooling of samples should be done with caution, as it could decrease the accuracy of diet estimations relative to the separate analysis of samples, especially for detecting species that occur at relatively low abundance (Mata et al., 2019). The number of pollen grains present in a sample will vary according to the sample type. For pollen collected directly from the bodies of pollinators, this will vary according to pollinator species. Estimates show that Hymenoptera can carry relatively high numbers of pollen grains (Apis mellifera and Bombus lucorum carry 2100-2500 pollen grains; Bombus pascuorum , 800 grains), Diptera carry fewer (Syrphidae 500 grains; Empididae $\sim 80$ grains), and Lepidoptera carry fewer again ( 20 grains), while the few Coleoptera observed carried up to 200 grains (Pornon et al., 2016). The number of samples collected, whether they are pooled, the number of sampling events across time and space, and the replication level within each of these samples will depend on the questions being addressed. Once the pollen samples are obtained, they seem to be relatively resilient and easily storable over extended periods under different conditions without introducing biases (e.g., frozen, room temperature, silica gel dried; Quaresma et al., 2021).

Control samples should be used to validate the methodology for each study system. These include negative controls, ideally including field-collected and laboratory blanks, to assess for contaminating DNA from external sources, and positive controls or mock communities to demonstrate that the sequencing method is effective, and if relevant, quantitative, for the species in the study system. Contamination should also be minimised through good laboratory practice. Extra precautions can be taken for specific sample types, such as using separate collection materials (i.e., nets, vials) to avoid cross-contamination between specimens during collection (Pornon et al., 2016). For some sample types, contamination will be unavoidable. For example, some types of nest pollen from solitary bees may be contaminated by other plant DNA during nest construction (Gresty et al., 2018; Alexander Keller et al., 2015; McFrederick \& Rehan, 2016). Finally, analysis of negative controls will allow for detection and removal of contaminating sequences during the bioinformatics step (e.g., Davis, Proctor, Holmes, Relman, \& Callahan, 2018).

Step 2: Selecting appropriate gene region(s) and creating a reference database

The standard DNA barcode for plants is $r b c L$ and matK (CBOL Plant Working Group et al., 2009), but other gene regions such astrnL, ITS1 and ITS2 are often used, especially for DNA metabarcoding as they have shown deeper resolution for several taxonomic groups (Wilson et al., 2021). Increasing the number and length of gene regions is expected to improve taxonomic resolution, and some studies on pollen mixtures have 
used whole plastid genomes (Lang et al., 2019) or whole genomes (Bell, Petit, et al., 2021). The barcode gene region(s) must be suitable for differentiating the taxa in the study system to the taxonomic level required and have primers universal enough to amplify all taxa. Recent research has shown a combination of $r b c L$ and ITS2 to work better than other combinations for detecting the highest number of species at the lowest level of taxonomic discrimination (Jones, Twyford, et al., 2021). Several studies have worked towards developing more universal primers for ITS2 (e.g., Kolter \& Gemeinholzer, 2021; Moorhouse-Gann et al., 2018) and primers to amplify shorter regions to account for pollen degradation in historical samples (Simanonok et al., 2021). More gene regions (and partial or whole genomes) lead to improved taxonomic resolution but also require more work in assembling the reference library. Using multiple gene regions has the additional challenge of determining the best method of combining results from different markers, with differing taxonomic resolution, for downstream analysis.

It is essential for the gene regions to have a comprehensive reference library for the species in the study system. Using a custom, relevant reference library reduces misidentifications and increases the accuracy of taxonomic assignments (Arstingstall et al., 2021; A. Keller et al., 2020). Software such as the BCdatabaser (A. Keller et al., 2020) for creating custom databases from species lists can be helpful where there is no national database, different gene regions are being used, or a more local database is desired. In addition, the recent software MetaCurator of Richardson, Sponsler, McMinn-Sauder, and Johnson (2020) has two advantageous features to curate existing or generated reference datasets: 1) identifying the exact amplicon of interest and trimming away extraneous sequence to avoid non-overlapping amplicons of the same gene, and 2) dereplicating sequences by taxonomy so that barcodes are retained for multiple species even when there is no barcode gap (i.e., a higher and non-overlapping range of sequence divergence between species than among species). A consideration of this and many other methods is that they create a static database that needs to be updated frequently as new sequences become available.

\section{Step 3: Isolating and sequencing DNA}

Isolating DNA from pollen is relatively straightforward. First, the pollen is lysed, usually through beadbeating. There are off-the-shelf kits that work well, along with cheaper extraction methods based on phenol and chloroform; acetone-based DNA isolation has also been effective (Gouker, Guo, \& Pooler, 2020). Some studies have shown that it is possible to extract and sequence DNA from pollen without a lysing step (Swenson \& Gemeinholzer, 2021). The high-throughput capabilities of DNA metabarcoding are reliant on the addition of sample-specific nucleotides which allow the identification of hundreds of individual samples following pooling into a single sample sent for sequencing (multiplexing). Three multiplexing methods are commonly used, and the most appropriate method should be chosen based on an assessment of the risk of cross-contamination, PCR efficiency and overall cost (reviewed in Bohmann et al., in press). For sequencing, most amplicon-based studies use the Illumina MiSeq platform with v3 chemistry (300 paired-end sequencing, 600 cycle) to sequence 300-550 base pair reads. New long-read sequencing technologies could add improved taxonomic resolution. These methods are discussed further in section 5 .

Step 4: Bioinformatic analysis to compare sequencing reads to reference databases

Bioinformatic procedures are required to assign taxonomic identifications to the sequence reads. There are numerous bioinformatic pipelines for analysing amplicon sequencing data including but not limited to QIIME2 (Bolyen et al., 2019), dada2 (Callahan et al., 2016), VSEARCH (Rognes, Flouri, Nichols, Quince, \& Mahe, 2016), USEARCH (Edgar, 2010), and OBItools (Boyer et al., 2016), as well as custom pipelines developed specifically for pollen metabarcoding (e.g., Ford and Jones, 2020). All these pipelines share a few main steps, which are not necessarily performed in the same order as described here. 1) In most cases paired-end data is obtained for Illumina sequencing runs. In many pipelines, the forward and reverse reads are merged, low-quality reads removed, and low-quality bases are trimmed from reads. Some paired-end read mergers such as PEAR (Zhang, Kobert, Flouri, \& Stamatakis, 2014) also remove adapter sequences (technical sequences added during HTS library preparation). 2) Reads are demultiplexed based on tags used in the metabarcoding primer, or tags that are added to each sample during HTS library preparations. 3) Reads are dereplicated and denoised to cluster sequences together which likely differ only by PCR errors. 
There are some approaches such as the Amplicon Sequence Variant (ASV) (Callahan et al., 2016) which have been applied to pollen (Casanelles-Abella et al., 2021; Elliott et al., 2020; Wilson et al., 2021). 4) Taxonomic assignment using reference databases. Finally, 5) the creation of a Taxon table or mOTU table containing the number of reads assigned to each taxon per sample. The Taxon table can be further filtered to remove noise and contaminants based on extraction and PCR controls.

Limitations, technical issues, and progress

One of the ongoing challenges associated with DNA-based identification of species mixtures is quantifying the relative abundance of species in the mixture. The issue of quantification is likely to be relevant for many applications in assessing global ecological change. Many ecosystem changes initially present as changes in species abundances rather than changes in species composition. Solutions to the technical problem of quantification could differ for pollen relative to other sample types, although the issues are similar in many ways. DNA metabarcoding is considered semi-quantitative. Species in high proportions are usually represented by many sequencing reads, although the relationship often deviates from the expected 1:1 ratio (Bell et al., 2019; Marcel Polling et al., 2022). There are several reasons for this deviation. Different pollen types can have different DNA extraction efficiencies, which can be improved with method optimisation. Variation occurs among species in the copy numbers of the DNA barcodes, and this has been well-studied for microbes, with the possibility to correct for these biases (Kembel, Wu, Eisen, \& Green, 2012; Lamb et al., 2019; Pawluczyk et al., 2015) and a recent study on mitogenomics of insects has applied corrections for copy number (L. Garrido-Sanz et al., 2021). An additional source of bias comes from differences among species in primer binding efficiency (Pompanon et al., 2012) and biases in DNA polymerase binding efficiencies towards different nucleotide compositions (Nichols et al., 2018). These biases can be reduced with careful primer design and PCR optimisation and can be corrected with a good understanding of the biases.

Amplification-free methods eliminate the PCR biases and have been shown in a handful of studies to be more quantitative than DNA metabarcoding. Whole-genome shotgun (WGS) sequencing has been shown to have improved quantification for pollen (Bell, Petit, et al., 2021) and other mixtures of eukaryote species (Lidia Garrido-Sanz, Senar, \& Pinol, 2020). Genome-skimming of organellar DNA from WGS has been shown to be quantitative for pollen (Lang et al., 2019) and other eukaryote mixtures (Bista et al., 2018), and quantification can be improved by correcting for organelle copy number (L. Garrido-Sanz et al., 2021). Reduced-representation sequencing using endonucleases (genotyping-by-sequencing) of plant roots has shown within- and across-species abundances strongly correlate with biomass-based species abundance (Wagemaker et al., 2021). Reverse Metagenomics, the sequencing of samples using MinION long reads while reference sequences come from short read skims, has also been found to be semi-quantitative (Peel et al., 2019). While most DNA-based detection and identification methods are semi-quantitative, there is considerable value in the relative read abundances, which are lost by treating data as presence-absence (Deagle et al., 2019). Improved quantification is expected to become possible in the future with an improved understanding of biases.

A related problem is understanding the sensitivity of DNA metabarcoding and the expected detection limits for species of interest, and the rates of false positives and false negatives. This issue may be particularly relevant to biosurveillance and ecosystem monitoring applications, where researchers and managers may be interested in changes in the presence or absence of low abundance species, such as a rare species becoming extinct or early detections of new incursions of non-native invasive species. Acceptable levels of false positives and false negatives will differ among applications. For example, for a risk-averse strategy detecting invasive species, it is important to avoid false negatives. In contrast, for detecting threatened species, a more riskaverse approach would avoid false positives. In both cases, a level of confidence is needed for the detection of a target species. These issues have been addressed with methods for the eDNA of water samples. For example, eDNA has been combined with site occupancy models to determine the confidence of presence/absence results (Dorazio \& Erickson, 2018; Schmidt et al., 2013), and similar methods would be applicable to pollen.

Improved confidence in the presence of a species in a sample can be obtained by understanding the overall rate of false positives and false negatives for the study system and method. Researchers can increase confidence 
by using field-based and laboratory-based negative controls and positive controls or mock communities and the use of no-library negative controls to quantify sequencing mistag rates (Esling, Lejzerowicz, \& Pawlowski, 2015). However, confidence estimates are also lacking for the classification steps in pollen DNA metabarcoding. There is an additional need for developing classification programs with more accurate probabilistic confidence estimates. While this has been attempted several times, available methods do not provide consistent results depending on the gene regions and databases used (Edgar, 2018).

Another challenge for pollen DNA metabarcoding and related methods is the development of reference databases. There are an estimated 450,000 angiosperm species (Pimm \& Joppa, 2015), and currently, around $25 \%$ of these have publicly available sequences for standard DNA barcodes (Bell, Petit, et al., 2021). Reference libraries have been compiled for standard DNA barcodes for all flowering plants in the UK (Jones, Twyford, et al., 2021) and Canada (Kuzmina et al., 2017). There is ongoing work in other countries to develop national databases. There are fewer references available for non-standard DNA barcodes, plastomes, genome skims, and assembled genomes (Bell, Petit, et al., 2021; Lang et al., 2019). Several large-scale projects are in progress to sequence DNA barcodes, organellar genomes and whole genomes for a large proportion of global biodiversity (Lewin et al., 2018), and therefore, the availability of reference sequences is continually improving. Additional problems occur with the quality of publicly available sequences. While quality control standards for databases such as BOLD are high, databases such as GenBank depend on researchers depositing data to conduct their quality control, and only minimal checks are performed, and many erroneous sequences have been found (Breitwieser, Pertea, Zimin, \& Salzberg, 2019). For most studies, it will be necessary to develop a custom, curated database, including sequencing any species in the study system that do not already have reliable sequences on public databases. Filtering and subsetting public reference databases to species of interest (e.g., the regional species pool) can be a helpful step in classification to help avoid misclassifications to closely related species (A. Keller et al., 2020). This step is likely to remain useful, even as reliable public databases become more complete.

The ability to assess global ecological change often relies on the comparison of contemporary data to historical data. Pollen DNA metabarcoding methods have only been developed recently, so there are no equivalent historical datasets. Baseline data from earlier studies based on other methods may not be directly comparable to pollen DNA metabarcoding. For example, studies have shown that the networks assembled through pollen DNA metabarcoding are more connected than those assembled through observations (Arstingstall et al., 2021; Pornon et al., 2017), although networks assembled through traditional identification methods of pollinatorcollected pollen may be more like those assembled through DNA metabarcoding, i.e., more connected (Bosch et al., 2009). There is potential to obtain equivalent historical data by analysing historical specimens using DNA sequencing technologies (Gous et al., 2019; Simanonok et al., 2021). Still, assessments are needed to see if there are any biases due to degradation over time. Likewise, pollen in sediments could provide a source of material for comparison with modern pollen DNA metabarcoding or other DNA-based methods (Niemeyer et al., 2017). Finally, as we move into the future, it will be essential to retain and archive specimens for optimum preservation to be reanalysed and compared to future samples.

To date, there has been little standardisation in the methods used for sequence-based characterisation of pollen communities in terms of databases, classifiers, gene regions, or other options. There is also inconsistency in how the methods are described and results reported in the literature making comparisons of techniques difficult. While this allows for greater flexibility and more scope for further method development, standardisation would facilitate consistent benchmarking of procedures to improve confidence. Once again, the fields of aquatic eDNA and microbiomics are more advanced in this regard, with several recommendations and standardised methods available (Loeza-Quintana, Abbott, Heath, Bernatchez, \& Hanner, 2020; Yilmaz et al., 2011). There are many choices on methodology at all stages of a research project, including: gene region(s), DNA extraction, PCR, sequencing technologies, and data analysis. Standardisation becomes possible once available methods have been compared, assessed, and optimised. From this, minimum sets of standards can be determined for replication, negative and positive controls, and optimal choices across sampling, sequencing, and data analysis steps. These standards can then be applied when designing a project and when assessing papers during peer-review. Some methods for the various steps involved in pollen DNA 
metabarcoding have been compared (Swenson \& Gemeinholzer, 2021; Tommasi, Ferrari, Labra, Galimberti, \& Biella, 2021), however, there remains a lot of work to be done before any general recommendations can be made.

\section{Future research directions}

In addition to the work currently in progress to solve the technical issues discussed in section 4 , we have identified several areas where method development on pollen DNA metabarcoding and related methods could open new avenues of research. These include method developments for intraspecific identification, analysis of DNA from ancient pollen, increased use of specimens available in museums and herbaria, and increased use of newer sequencing technologies.

Intraspecific identifications (e.g., populations, individuals) using DNA sequencing of pollen could open new research areas on the role of pollinators in gene flow, and the effects of habitat fragmentation on plant and pollinator health and adaptive potential. Recent developments with eDNA suggest that this is plausible for pollen. For example, eDNA has been used to investigate intraspecific variation in the mitochondrial control region of whale sharks in sea water (Sigsgaard et al., 2016), cytb variation in harbour porpoises (Parsons, Everett, Dahlheim, \& Park, 2018), and microsatellite allele frequencies in artificial mesocosms of round gobies (Neogobius melanostomus ) (Andres, Sethi, Lodge, \& Andres, 2021). Genomic DNA from Late Pleistocene bears was retrieved from shotgun data showing that it might be possible to use ancient eDNA for intra-species analysis (Pedersen et al., 2021). Applying target capture of mitochondrial and nuclear DNA in eDNA is also a promising avenue of research (Jensen et al., 2021). All the previous investigations into intraspecific variation from eDNA have been attempted in aquatic study systems and cave sediments, and, as far as we know, have not been attempted on plant communities or pollen. Pollen mixtures might be the ideal candidate system to investigate intraspecific variation. Because all individual pollen grains in a mixture represent an individual gametophyte, any method focusing on the genetic content of a single pollen grain can be used to investigate the mixture on a population level. While population level inferences might be possible without sequencing single pollen grains, many population genomics tools require sequence data of individuals. To overcome problems with single pollen grain sequencing, such as low template abundance and uncertainties about whether DNA is coming from inside the pollen or fragments sticking to the outside, it might be beneficial to germinate the pollen to make accessing the DNA easier (Jayaprakash, 2018). Current advances in the read output and length in HTS platforms coupled with the potential to sequence individual pollen grains might advance molecular pollen analysis beyond species identification. As soon as the DNA inside individual pollen grains can be accessed, amplified, and sequenced, the road to a whole new set of research questions can be opened. For example, applying population genomics to not only count the number of species, but also quantify how many individual plants a pollinator has visited.

The high level of preservation of pollen morphology in ancient sedimentary records, means that pollen is often used to understand past ecosystems. Coupling these methods with ancient DNA technology could provide narrower taxonomic identification and more fine scale understanding of past ecosystems. Although it has been demonstrated that DNA is present in ancient pollen and can be sequenced (Bennett \& Parducci, 2006; L. Parducci et al., 2005), ancient pollen samples are difficult to process and there is a high risk of contamination with exogenous DNA. There are many different approaches for isolating and cleaning single pollen grains from the abundant pollen usually present in sediments. These include hand pipetting under a microscope, serial dilution, flow-assisted cell sorting (flow cytometry), microfluidic manipulation (Wang \& Navin, 2015), flow sorting or micro-manipulation (Kron \& Husband, 2012). Potential method development in this area could focus on improved efficiency and contamination control. Once these issues are addressed, there is great promise for ancient pollen analysis to reveal ecosystem change over large time scales.

Likewise, there is currently an unrealised potential to use herbarium and museum specimens to answer questions in global change ecology. Currently, a handful of studies have shown that preserved specimens can be used to study plant-pollinator interactions. Methods have been developed for identifying historical pollen samples from bees using metabarcoding (Gous et al., 2019). Museum specimens can be used to assess resource use over huge temporal scales. For example, Simanonok et al. (2021) identified resource use by 
Bombus affinis over 100 years, and found that pollen richness and diversity had not changed over time and neither had the abundance of native nor introduced species. This work helps understand drivers behind the decline of native pollinator species. Historical specimens can also be used not only for temporal analysis of forage use but can help increase sample size for spatial analysis. For example, Gous, Eardley, Johnson, Swanevelder, and Willows-Munro (2021) sampled pollen from museum specimens of multiple species from varying regions in South Africa across large temporal scale to assess the relationship between resource use and geographic range of species. There is similar potential to use herbarium specimens to look at past distributions and morphology of plants to check for plant-pollinator mismatches.

Finally, future advances in sequencing technology could influence how pollen DNA metabarcoding and related methods are used for studying ecological change. New fast, portable, sequencing technologies, such as Oxford Nanopore Technologies' MinION, could allow for analysis while in the field. Increased throughput of short read sequencing technologies (e.g., Illumina NovaSeq), could make high-throughput analysis of pollen samples faster and more cost-effective. Improvements in accuracy of PacBio HiFi long-read sequencing could make it suitable for DNA metabarcoding and related methods. However, many of these sequencing platforms currently require a very high quality and quantity of DNA. As sequencing technologies improve, they may require lower quantities of DNA making them increasingly useful for pollen DNA analysis, especially of pollen from small insects, single pollen grains, or ancient pollen.

Metagenomics methods depend on reference databases of whole genomes or whole plastid genomes. However, new initiatives, such as the Earth BioGenome Project, which aims to sequence the genomes of most eukaryote species within a decade (Lewin et al., 2018), have the potential to alleviate this limitation in the future. In addition, there are metagenomics methods based on long-read sequencing that could improve the resolution and quantification of pollen identification, without the need for whole genome reference databases. For example, the RevMet (reverse metagenomics) method of Peel et al. (2019) uses long-read nanopore sequences of samples, while the reference database contains low coverage short-read genome skims. This strategy could potentially increase resolution and quantification relative to DNA metabarcoding and could have cost advantages over other metagenomics methods as it does not require assembled genomes for the reference database. An alternative approach is provided by reduced-representation sequencing for metagenomics. For example, the sequencing of restriction fragments (ddRAD) has been used to identify plant community composition from roots in soil samples (Wagemaker et al., 2021), and the same methods could easily be applied to pollen mixtures. Given the rapid advancements in sequencing technology and the increasing availability of reference sequences and genomes, method development for DNA-based identification of pollen should be considered a work in progress; each new study will need to carefully consider the strengths and weaknesses of the methods available or likely to become available during the study.

\section{Conclusions}

In recent years, there have been increasing numbers of studies applying pollen DNA metabarcoding and related methods to research questions on global change ecology (Fig. 1). Pollen DNA metabarcoding has provided advantages over other methods in throughput and requiring less taxonomic expertise. The potential applications of pollen DNA metabarcoding and related methods are likely to increase as reference databases improve, methods are assessed against traditional approaches and standardised, and as multi-year datasets are accumulated.

Currently, pollen DNA metabarcoding is complementary to traditional methods, such as microscopic identification of pollen and direct observation of plant-pollinator interactions. This is particularly the case where baseline data exists and has been collected through traditional methods. However, there are cases where samples have been captured and preserved: e.g., museum specimens of pollinators (Gous et al., 2021; Simanonok et al., 2021), slides of pollen collections (Marcel Polling et al., 2022), and these have been analysed through DNA metabarcoding, providing scope to analyse contemporary and historical samples, and assess changes from baseline ecological conditions. As more long-term studies are completed using DNA metabarcoding, these methods could be used to understand recent change. Under these scenarios, pollen DNA metabarcoding and related methods could eventually become more predominant, especially given the benefits in terms 
of high-throughput for large sample sizes, and in combination with other newer technologies, such as flow cytometry (Kron et al., 2021) and machine-learning classifications (Goncalves et al., 2016) .

Global ecological change is happening rapidly, and high-throughput methods are essential for getting timely data on changes so that management practices can be assessed and changed as required. Pollen DNA metabarcoding and related methods are important tools for rapid, high-throughput assessment of ecosystem change, providing real-time management recommendations to preserve biodiversity and the evolutionary and ecological process that support it before it is too late.

Acknowledgements

The manuscript was improved with comments from Olly Berry and Liz Milla. RML is supported by the Biotechnology and Biological Sciences Research Council (BBSRC), part of UK Research and Innovation, through Core Strategic Programme Grant BB/CSP1720/1.

Author contributions

Determining the scope of the paper: KLB (lead), in discussion with all authors. Compiling literature: KLB, FE-V, AK, KN, RR, KT, AL, RML, NdV. Analysis of literature and creating figures and tables: KT. Writing first draft: KLB (lead), BB, KSB. Editing and reviewing the manuscript: all authors. All authors approved of the final submitted manuscript.

\section{References}

Ancin-Murguzur, F. J., Munoz, L., Monz, C., \& Hausner, V. H. (2020). Drones as a tool to monitor human impacts and vegetation changes in parks and protected areas. Remote Sensing in Ecology and Conservation, 6 , 105-113. doi: $10.1002 / \mathrm{rse} 2.127$

Anderegg, W. R. L., Abatzoglou, J. T., Anderegg, L. D. L., Bielory, L., Kinney, P. L., \& Ziska, L. (2021). Anthropogenic climate change is worsening North American pollen seasons. Proc Natl Acad Sci U S A, 118 (7). doi:10.1073/pnas.2013284118

Andres, K. J., Sethi, S. A., Lodge, D. M., \& Andres, J. (2021). Nuclear eDNA estimates population allele frequencies and abundance in experimental mesocosms and field samples. Molecular Ecology, 30 (3), 685-697. doi:10.1111/mec.15765

Arstingstall, K. A., DeBano, S. J., Li, X., Wooster, D. E., Rowland, M. M., Burrows, S., \& Frost, K. (2021). Capabilities and limitations of using DNA metabarcoding to study plant-pollinator interactions. Mol Ecol . doi:10.1111/mec.16112

Aziz, A. N., \& Sauve, R. J. (2008). Genetic mapping of Echinacea purpurea via individual pollen DNA fingerprinting. Molecular Breeding, 21 (2), 227-232. doi:10.1007/s11032-007-9123-9

Baksay, S., Pornon, A., Burrus, M., Mariette, J., Andalo, C., \& Escaravage, N. (2020). Experimental quantification of pollen with DNA metabarcoding using ITS1 and trnL. Scientific Reports, 10 (1), 4020. doi:10.1038/s41598-020-61198-6

Baldock, K. C., Goddard, M. A., Hicks, D. M., Kunin, W. E., Mitschunas, N., Osgathorpe, L. M., . . . Memmott, J. (2015). Where is the UK's pollinator biodiversity? The importance of urban areas for flower-visiting insects. Proc Biol Sci, 282 (1803), 20142849. doi:10.1098/rspb.2014.2849

Bansch, S., Tscharntke, T., Wunschiers, R., Netter, L., Brenig, B., Gabriel, D., \& Westphal, C. (2020). Using ITS2 metabarcoding and microscopy to analyze shifts in pollen diets of honey bees and bumble bees along a mass-flowering crop gradient. Molecular Ecology, 29 (24), 5003-5018.

Bartomeus, I., Ascher, J. S., Wagner, D., Danforth, B. N., Colla, S., Kornbluth, S., \& Winfree, R. (2011). Climate-associated phenological advances in bee pollinators and bee-pollinated plants. Proceedings of the National Academy of Sciences, 108 (51), 20645-20649. doi:10.1073/pnas.1115559108 
Bell, K. L., Batchelor, K. L., Bradford, M., McKeown, A., Macdonald, S. L., \& Westcott, D. (2021). Optimisation of a pollen DNA metabarcoding method for diet analysis of flying-foxes $(<\mathrm{i}>$ Pteropus $</ \mathrm{i}>$ spp.).Australian Journal of Zoology , -. doi:https://doi.org/10.1071/ZO20085

Bell, K. L., Burgess, K. S., Botsch, J. C., Dobbs, E. K., Read, T. D., \& Brosi, B. J. (2019). Quantitative and qualitative assessment of pollen DNA metabarcoding using constructed species mixtures. InMolecular Ecology (Vol. 28, pp. 431-455): Wiley/Blackwell (10.1111).

Bell, K. L., de Vere, N., Keller, A., Richardson, R. T., Gous, A., Burgess, K. S., \& Brosi, B. J. (2016). Pollen DNA barcoding: current applications and future prospects. Genome, 59 (9), 629-640. doi:10.1139/gen-20150200

Bell, K. L., Petit, R. A., Cutler, A., Dobbs, E. K., Macpherson, J. M., Read, T. D., . . . Brosi, B. J. (2021). Comparing whole-genome shotgun sequencing and DNA metabarcoding approaches for species identification and quantification of pollen species mixtures. Ecology and Evolution . doi:10.1002/ece3.8281

Bennett, K., \& Parducci, Y. (2006). DNA from pollen: principles and potential. In The Holocene (Vol. 16, pp. 1031-1034).

Berry, D., Mahfoudh, K. B., Wagner, M., \& Loy, A. (2011). Barcoded Primers Used in Multiplex Amplicon Pyrosequencing Bias Amplification.Applied and Environmental Microbiology, 77 (21), 7846-7849. doi:doi:10.1128/AEM.05220-11

Bista, I., Carvalho, G. R., Tang, M., Walsh, K., Zhou, X., Hajibabaei, M., . . . Creer, S. (2018). Performance of amplicon and shotgun sequencing for accurate biomass estimation in invertebrate community samples. In Molecular Ecology Resources (Vol. 18, pp. 1020-1034).

Bolyen, E., Rideout, J. R., Dillon, M. R., Bokulich, N. A., Abnet, C. C., Al-Ghalith, G. A., . . . Caporaso, J. G. (2019). Reproducible, interactive, scalable and extensible microbiome data science using QIIME 2. Nature Biotechnology, 37 (8), 852-857. doi:10.1038/s41587-019-0209-9

Bosch, J., Gonzalez, A. M., Rodrigo, A., \& Navarro, D. (2009). Plant-pollinator networks: adding the pollinator's perspective.Ecol Lett, 12 (5), 409-419. doi:10.1111/j.1461-0248.2009.01296.x

Bourel, B., Marchant, R., de Garidel-Thoron, T., Tetard, M., Barboni, D., Gally, Y., \& Beaufort, L. (2020). Automated recognition by multiple convolutional neural networks of modern, fossil, intact and damaged pollen grains. Computers \& Geosciences, 140 , 104498. doi:10.1016/j.cageo.2020.104498

Bowler, D. E., Bjorkman, A. D., Dornelas, M., Myers-Smith, I. H., Navarro, L. M., Niamir, A., . . . Fish, R. (2020). Mapping human pressures on biodiversity across the planet uncovers anthropogenic threat complexes. People and Nature, 2 (2), 380-394. doi:10.1002/pan3.10071

Boyer, F., Mercier, C., Bonin, A., Le Bras, Y., Taberlet, P., \& Coissac, E. (2016). obitools: a unix-inspired software package for DNA metabarcoding. Molecular Ecology Resources, 16 (1), 176-182. doi:10.1111/17550998.12428

Breitwieser, F. P., Pertea, M., Zimin, A. V., \& Salzberg, S. L. (2019). Human contamination in bacterial genomes has created thousands of spurious proteins. Genome Research, 29 (954-960). doi:10.1101/gr.245373.118

Brennan, G. L., Potter, C., de Vere, N., Griffith, G. W., Skjoth, C. A., Osborne, N. J., . . . Creer, S. (2019). Temperate airborne grass pollen defined by spatio-temporal shifts in community composition. Nature Ecology 83 Evolution, 3 (5), 750-754. doi:10.1038/s41559-019-0849-7

Brosi, B. J. (2016). Pollinator specialization: from the individual to the community. New Phytologist, 210 (4), 1190-1194. doi:10.1111/nph.13951

Brosi, B. J., \& Briggs, H. M. (2013). Single pollinator species losses reduce floral fidelity and plant reproductive function.Proceedings of the National Academy of Sciences, 110 (32), 13044-13048. 
doi:10.1073/pnas.1307438110

Bruni, I., Galimberti, A., Caridi, L., Scaccabarozzi, D., De Mattia, F., Casiraghi, M., \& Labra, M. (2015). A DNA barcoding approach to identify plant species in multiflower honey. In Food chemistry (Vol. 170, pp. 308-315).

Burkle, L. A., Marlin, J. C., \& Knight, T. M. (2013). Plant-pollinator interactions over 120 years: Loss of species, co-occurrence, and function. Science, 339 (6127), 1611-1615.

Butchart, S. H. M., Walpole, M., Collen, B., van Strien, A., Scharlemann, J. P. W., Almond, R. E. A., . . . Watson, R. (2010). Global biodiversity: Indicators of recent declines. Science, 328 (5982), 1164-1168.

Callahan, B. J., McMurdie, P. J., Rosen, M. J., Han, A. W., Johnson, A. J., \& Holmes, S. P. (2016). DADA2: High-resolution sample inference from Illumina amplicon data. Nature Methods, 13 (7), 581-583. doi:10.1038/nmeth.3869

Campbell, B. C., Al Kouba, J., Timbrell, V., Noor, M. J., Massel, K., Gilding, E. K., . . . Davies, J. M. (2020). Tracking seasonal changes in diversity of pollen allergen exposure: Targeted metabarcoding of a subtropical aerobiome. Science of The Total Environment, 747, 141189. doi:10.1016/j.scitotenv.2020.141189

Capo, E., Giguet-Covex, C., Rouillard, A., Nota, K., Heintzman, P. D., Vuillemin, A., . . . Parducci, L. (2021). Lake Sedimentary DNA Research on Past Terrestrial and Aquatic Biodiversity: Overview and Recommendations. Quaternary, 4 (1), 6. doi:10.3390/quat4010006

Casanelles-Abella, J., Muller, S., Keller, A., Aleixo, C., Alos Orti, M., Chiron, F., . . . Moretti, M. (2021). How wild bees find a way in European cities: Pollen metabarcoding unravels multiple feeding strategies and their effects on distribution patterns in four wild bee species. Journal of Applied Ecology . doi:10.1111/13652664.14063

CBOL Plant Working Group, Hollingsworth, P. M., Forrest, L. L., Spouge, J. L., Hajibabaei, M., Ratnasingham, S., . . . Little, D. P. (2009). A DNA barcode for land plants. Proceedings of the National Academy of Sciences, 106 (31), 12794-12797. doi:10.1073/pnas.0905845106

Chang, H., Guo, J., Fu, X., Liu, Y., Wyckhuys, K., Hou, Y., \& Wu, K. (2018). Molecular-Assisted Pollen Grain Analysis Reveals Spatiotemporal Origin of Long-Distance Migrants of a Noctuid Moth. InInternational Journal of Molecular Sciences (Vol. 19, pp. 567): Multidisciplinary Digital Publishing Institute.

Cohen, H., Smith, G. P., Sardinas, H., Zorn, J. F., McFrederick, Q. S., Woodard, S. H., \& Ponisio, L. C. (2021). Mass-flowering monoculture attracts bees, amplifying parasite prevalence. Proceedings of the Royal Society B: Biological Sciences, 288 (1960), 20211369. doi:doi:10.1098/rspb.2021.1369

Courtin, J., Andreev, A. A., Raschke, E., Bala, S., Biskaborn, B. K., Liu, S., . . . Herzschuh, U. (2021). Vegetation Changes in Southeastern Siberia During the Late Pleistocene and the Holocene. Frontiers in Ecology and Evolution, 9 . doi:10.3389/fevo.2021.625096

Cristescu, M. E. (2014). From barcoding single individuals to metabarcoding biological communities: towards an integrative approach to the study of global biodiversity. In Trends in Ecology 83 Evolution (Vol. 29, pp. 566-571): Elsevier Ltd.

Cullen, N., Xia, J., Wei, N., Kaczorowski, R., Arceo-Gomez, G., O’Neill, E., . . . Ashman, T.-L. (2021). Diversity and composition of pollen loads carried by pollinators are primarily driven by insect traits, not floral community characteristics. Oecologia, 196 (1), 131-143. doi:10.1007/s00442-021-04911-0

da Rocha-Filho, L. C., Montagnana, P. C., Araujo, T. N., Moure-Oliveira, D., Boscolo, D., \& Garofalo, C. A. (2021). Pollen analysis of cavity-nesting bees (Hymenoptera: Anthophila) and their food webs in a city. Ecological Entomology . doi:10.1111/een.13097

Damschen, E. I., Brudvig, L. A., Burt, M. A., Fletcher, R. J., Haddad, N. M., Levey, D. J., . . . Tewksbury, J. J. (2019). Ongoing accumulation of plant diversity through habitat connectivity in an 18-year experiment. 
Science, 365 (6460), 1478-1480. doi:doi:10.1126/science.aax8992

Danner, N., Keller, A., Hartel, S., \& Steffan-Dewenter, I. (2017). Honey bee foraging ecology: Season but not landscape diversity shapes the amount and diversity of collected pollen. In W. Blenau (Ed.),PLoS one (Vol. 12, pp. e0183716): Springer New York.

Darling, J. A., Pochon, X., Abbott, C. L., Inglis, G. J., \& Zaiko, A. (2020). The risks of using molecular biodiversity data for incidental detection of species of concern. Diversity and Distributions, 26 (9), 11161121. doi:10.1111/ddi. 13108

Davis, N. M., Proctor, D. M., Holmes, S. P., Relman, D. A., \& Callahan, B. J. (2018). Simple statistical identification and removal of contaminant sequences in marker-gene and metagenomics data. InMicrobiome (Vol. 6, pp. 226): BioMed Central.

de Manincor, N., Hautekeete, N., Mazoyer, C., Moreau, P., Piquot, Y., Schatz, B., . . . Massol, F. (2020). How biased is our perception of plant-pollinator networks? A comparison of visit- and pollen-based representations of the same networks. Acta Oecologica, 105 , 103551. doi:10.1016/j.actao.2020.103551

de Vere, N., Jones, L. E., Gilmore, T., Moscrop, J., Lowe, A., Smith, D., . . . Ford, C. R. (2017). Using DNA metabarcoding to investigate honey bee foraging reveals limited flower use despite high floral availability. In Scientific Reports (Vol. 7, pp. 42838).

Deagle, B. E., Thomas, A. C., McInnes, J. C., Clarke, L. J., Vesterinen, E. J., Clare, E. L., . . . Eveson, J. P. (2019). Counting with DNA in metabarcoding studies: How should we convert sequence reads to dietary data? Molecular Ecology, 28 (2), 391-406. doi:10.1111/mec.14734

Dharampal, P. S., Carlson, C., Currie, C. R., \& Steffan, S. A. (2019). Pollen-borne microbes shape bee fitness. Proceedings of the Royal Society B: Biological Sciences, 286 (1904), 20182894. doi:10.1098/rspb.2018.2894

Didham, R. K., Tylianakis, J. M., Gemmell, N. J., Rand, T. A., \& Ewers, R. M. (2007). Interactive effects of habitat modification and species invasion on native species decline. Trends Ecol Evol, 22 (9), 489-496. doi:10.1016/j.tree.2007.07.001

Diehn, S., Zimmermann, B., Tafintseva, V., Bağcıŏlu, M., Kohler, A., Ohlson, M., . . . Kneipp, J. (2020). Discrimination of grass pollen of different species by FTIR spectroscopy of individual pollen grains. Analytical and Bioanalytical Chemistry, 412 (24), 6459-6474. doi:10.1007/s00216-020-02628-2

Donkersley, P., Rhodes, G., Pickup, R. W., Jones, K. C., Power, E. F., Wright, G. A., \& Wilson, K. (2017). Nutritional composition of honey bee food stores vary with floral composition. Oecologia, 185 (4), 749-761. doi:10.1007/s00442-017-3968-3

Dorazio, R. M., \& Erickson, R. A. (2018). eDNAoccupancy: An R package for multiscale occupancy modelling of environmental DNA data.Molecular Ecology Resources, 18 (2), 368-380. doi:10.1111/17550998.12735

Douglas, M. R., Sponsler, D. B., Lonsdorf, E. V., \& Grozinger, C. M. (2020). County-level analysis reveals a rapidly shifting landscape of insecticide hazard to honey bees (Apis mellifera) on US farmland.Scientific Reports, 10 (1), 797. doi:10.1038/s41598-019-57225-w

Douglas, M. R., \& Tooker, J. F. (2015). Large-Scale Deployment of Seed Treatments Has Driven Rapid Increase in Use of Neonicotinoid Insecticides and Preemptive Pest Management in U.S. Field Crops.Environmental Science 83 Technology, 49 (8), 5088-5097. doi:10.1021/es506141g

Dunker, S., Motivans, E., Rakosy, D., Boho, D., Mäder, P., Hornick, T., \& Knight, T. M. (2021). Pollen analysis using multispectral imaging flow cytometry and deep learning. New Phytologist, 229 (1), 593-606. doi:10.1111/nph.16882

Dunn, J. C., Stockdale, J. E., Moorhouse-Gann, R. J., McCubbin, A., Hipperson, H., Morris, A. J., . . Symondson, W. O. C. (2018). The decline of the Turtle Dove: Dietary associations with body condition 
and competition with other columbids analysed using high-throughput sequencing. Molecular Ecology, 27, 3386-3407. doi:10.1111/mec.14766

Edgar, R. C. (2010). Search and clustering orders of magnitude faster than BLAST. Bioinformatics, 26 (19), 2460-2461. doi:10.1093/bioinformatics/btq461

Edgar, R. C. (2018). Accuracy of taxonomy prediction for 16S rRNA and fungal ITS sequences. PeerJ, 6 , e4652. doi:10.7717/peerj.4652

Elliott, B., Wilson, R., Shapcott, A., Keller, A., Newis, R., Cannizzaro, C., . . Wallace, H. M. (2020). Pollen diets and niche overlap of honey bees and native bees in protected areas. In Basic and Applied Ecology .

Ellis, E. C., Klein Goldewijk, K., Siebert, S., Lightman, D., \& Ramankutty, N. (2010). Anthropogenic transformation of the biomes, 1700 to 2000. Global Ecology and Biogeography, 19 , 589-606. doi:10.1111/j.14668238.2010.00540.x

Engel, P., Kwong, W. K., McFrederick, Q., Anderson, K. E., Barribeau, S. M., Chandler, J. A., . . Dainat, B. (2016). The Bee Microbiome: Impact on Bee Health and Model for Evolution and Ecology of Host-Microbe Interactions. mBio, 7 (2), e02164-02115. doi:10.1128/mBio.02164-15

Esling, P., Lejzerowicz, F., \& Pawlowski, J. (2015). Accurate multiplexing and filtering for high-throughput amplicon-sequencing. Nucleic Acids Research, 43 (5), 2513-2524. doi:10.1093/nar/gkv107

Forrest, J. R. K. (2015). Plant-pollinator interactions and phenological change: What can we learn about climate impacts from experiments and observations? Oikos (4-13).

Galimberti, A., De Mattia, F., Bruni, I., Scaccabarozzi, D., Sandionigi, A., Barbuto, M., . . Labra, M. (2014). A DNA barcoding approach to characterize pollen collected by honeybees. In PLoS one (Vol. 9, pp. e109363).

Garrido-Sanz, L., Senar, M. A., \& Pinol, J. (2021). Relative species abundance estimation in artificial mixtures of insects using mito-metagenomics and a correction factor for the mitochondrial DNA copy number. Mol Ecol Resour . doi:10.1111/1755-0998.13464

Garrido-Sanz, L., Senar, M. À., \& Piñol, J. (2020). Estimation of the relative abundance of species in artificial mixtures of insects using low-coverage shotgun metagenomics. In Metabarcoding and Metagenomics (Vol. 4, pp. e48281).

Gonçalves, A. B., Souza, J. S., da Silva, G. G., Cereda, M. P., Pott, A., Naka, M. H., \& Pistori, H. (2016). Feature extraction and machine learning for the classification of Brazilian savannah pollen grains.PLoS one, 11 (6), e0157044. doi:10.1371/journal.pone.0157044

Gouker, F. E., Guo, Y., \& Pooler, M. R. (2020). Using acetone for rapid PCR-amplifiable DNA extraction from recalcitrant woody plant taxa.Applications in Plant Sciences, 8 (12), e11403.

Gous, A., Eardley, C. D., Johnson, S. D., Swanevelder, D. Z. H., \& Willows-Munro, S. (2021). Floral hosts of leaf-cutter bees (Megachilidae) in a biodiversity hotspot revealed by pollen DNA metabarcoding of historic specimens. PLoS one, 16 (1), e0244973. doi:10.1371/journal.pone.0244973

Gous, A., Swanevelder, D. Z. H., Eardley, C. D., \& Willows-Munro, S. (2019). Plant-pollinator interactions over time: Pollen metabarcoding from bees in a historic collection. In Evolutionary Applications(Vol. 12, pp. 187-197): Wiley/Blackwell (10.1111).

Grab, H., Brokaw, J., Anderson, E., Gedlinske, L., Gibbs, J., Wilson, J., . . Diamond, S. (2019). Habitat enhancements rescue bee body size from the negative effects of landscape simplification. Journal of Applied Ecology, 56 (9), 2144-2154. doi:10.1111/1365-2664.13456

Gresty, C. E. A., Clare, E., Devey, D. S., Cowan, R. S., Csiba, L., Malakasi, P., . . W Willis, K. J. (2018). Flower preferences and pollen transport networks for cavity-nesting solitary bees: Implications for the design 
of agri-environment schemes. Ecology and Evolution, 8 (15), 7574-7587. doi:10.1002/ece3.4234

Hall, D. M., Camilo, G. R., Tonietto, R. K., Ollerton, J., Ahrné, K., Arduser, M., . . Threlfall, C. G. (2017). The city as a refuge for insect pollinators. Conserv Biol, 31 (1), 24-29. doi:10.1111/cobi.12840

Hansen, J., Reudy, R., Sato, M., \& Lo, K. (2010). Global surface temperature change. Reviews of Geophysics, 48 (RG4004), 2010RG000345.

Hasegawa, Y., Suyama, Y., \& Seiwa, K. (2009). Pollen donor composition during the early phases of reproduction revealed by DNA genotyping of pollen grains and seeds of Castanea crenata. New Phytologist, 182 (4), 994-1002. doi:10.1111/j.1469-8137.2009.02806.x

Hawkins, J., de Vere, N., Griffith, A., Ford, C. R., Allainguillaume, J., Hegarty, M. J., . . Adams-Groom, B. (2015). Using DNA Metabarcoding to Identify the Floral Composition of Honey: A New Tool for Investigating Honey Bee Foraging Preferences. In PLoS one(Vol. 10, pp. e0134735): Public Library of Science.

He, C., Liu, Z., Gou, S., Zhang, Q., Zhang, J., \& Xu, L. (2019). Detecting global urban expansion over the last three decades using a fully convolutional network. Environmental Research Letters, 14 (3), 034008. doi:10.1088/1748-9326/aaf936

Hirota, S. K., Nitta, K., Suyama, Y., Kawakubo, N., Yasumoto, A. A., \& Yahara, T. (2013). Pollinator-Mediated Selection on Flower Color, Flower Scent and Flower Morphology of Hemerocallis: Evidence from Genotyping Individual Pollen Grains On the Stigma. PLoS one, 8 (12), e85601. doi:10.1371/journal.pone.0085601

Hornick, T., Richter, A., Harpole, W. S., Bastl, M., Bohlmann, S., Bonn, A., . . . Dunker, S. (2021). An integrative environmental pollen diversity assessment and its importance for the Sustainable Development Goals. Plants, People, Planet . doi:10.1002/ppp3.10234

Hulme, P. E. (2009). Trade, transport and trouble: managing invasive species pathways in an era of globalization. Journal of Applied Ecology, 46 (1), 10-18. doi:https://doi.org/10.1111/j.1365-2664.2008.01600.x

Isagi, Y., \& Suyama, Y. (2011). Single-Pollen Genotyping . Tokyo: Springer.

Ito, M., Suyama, Y., Ohsawa, T. A., \& Watano, Y. (2008). Airborne-pollen pool and mating pattern in a hybrid zone betweenPinus pumila and P. parviflora var. pentaphylla .Molecular Ecology, 17 (23), 5092-5103. doi:10.1111/j.1365-294X.2008.03966.x

Jayaprakash, P. (2018). Pollen Germination in vitro. In P. W. Mokwala (Ed.), Pollination in Plants : IntechOpen.

Jensen, M. R., Sigsgaard, E. E., Liu, S., Manica, A., Bach, S. S., Hansen, M. M., . . Thomsen, P. F. (2021). Genome-scale target capture of mitochondrial and nuclear environmental DNA from water samples. Molecular Ecology Resources, 21 (3), 690-702. doi:10.1111/1755-0998.13293

Jones, L., Brennan, G. L., Lowe, A., Creer, S., Ford, C. R., \& de Vere, N. (2021). Shifts in honeybee foraging reveal historical changes in floral resources. Communications Biology, 4 (1), 37. doi:10.1038/s42003-020$01562-4$

Jones, L., Twyford, A. D., Ford, C. R., Rich, T. C. G., Davies, H., Forrest, L. L., . . de Vere, N. (2021). Barcode UK: A complete DNA barcoding resource for the flowering plants and conifers of the United Kingdom. Mol Ecol Resour, 21 (6), 2050-2062. doi:10.1111/1755-0998.13388

Judd, H. J., Huntzinger, C., Ramirez, R., \& Strange, J. P. (2020). A 3D Printed Pollen Trap for Bumble Bee (Bombus ) Hive Entrances.JoVE (161), e61500. doi:10.3791/61500

Kaluza, B. F., Wallace, H., Keller, A., Heard, T. A., Jeffers, B., Drescher, N., . . Leonhardt, S. D. (2017). Generalist social bees maximize diversity intake in plant species-rich and resource-abundant environments. In Ecosphere (Vol. 8, pp. e01758). 
Keller, A., Brandel, A., Becker, M. C., Balles, R., Abdelmohsen, U. R., Ankenbrand, M. J., \& Sickel, W. (2018). Wild bees and their nests host Paenibacillus bacteria with functional potential of avail.Microbiome, 6 (1), 229. doi:10.1186/s40168-018-0614-1

Keller, A., Danner, N., Grimmer, G., Ankenbrand, M. J., von der Ohe, K., von der Ohe, W., . . SteffanDewenter, I. (2015). Evaluating multiplexed next-generation sequencing as a method in palynology for mixed pollen samples. Plant Biology, 17 (2), 558-566. doi:10.1111/plb.12251

Keller, A., Hohlfeld, S., Kolter, A., Schultz, J., Gemeinholzer, B., \& Ankenbrand, M. J. (2020). BCdatabaser: on-the-fly reference database creation for (meta-)barcoding. Bioinformatics, 36 (8), 2630-2631. doi:10.1093/bioinformatics/btz960

Keller, A., McFrederick, Q. S., Dharampal, P., Steffan, S., Danforth, B. N., \& Leonhardt, S. D. (2021). (More than) Hitchhikers through the network: the shared microbiome of bees and flowers. Current Opinion in Insect Science, 44 , 8-15. doi:10.1016/j.cois.2020.09.007

Kembel, S. W., Wu, M., Eisen, J. A., \& Green, J. L. (2012). Incorporating 16S Gene Copy Number Information Improves Estimates of Microbial Diversity and Abundance. PLOS Computational Biology, 8 (10), e1002743. doi:10.1371/journal.pcbi.1002743

Khansaritoreh, E., Salmaki, Y., Ramezani, E., Akbari Azirani, T., Keller, A., Neumann, K., ... Behling, H. (2020). Employing DNA metabarcoding to determine the geographical origin of honey.Heliyon, 6 (11), e05596. doi:10.1016/j.heliyon.2020.e05596

Klimczak, L. J., Ebner von Eschenbach, C., Thompson, P. M., Buters, J. T. M., \& Meuller, G. A. (2020). Mixture analyses of air-sampled pollen extracts can accurately differentiate pollen taxa. Atmospheric Environment, 243 , 117746. doi:10.1016/j.atmosenv.2020.117746

Kolter, A., \& Gemeinholzer, B. (2021). Internal transcribed spacer primer evaluation for vascular plant metabarcoding. Metabarcoding and Metagenomics, 5 , e68155. doi:10.3897/mbmg.5.68155

Kortsch, S., Primicerio, R., Fossheim, M., Dolgov, A. V., \& Aschan, M. (2015). Climate change alters the structure of arctic marine food webs due to poleward shifts of boreal generalists. Proceedings of the Royal Society B: Biological Sciences, 282 , 20151546. doi:10.1098/rspb.2015.1546

Kraaijeveld, K., de Weger, L. A., Ventayol Garcia, M., Buermans, H., Frank, J., Hiemstra, P. S., \& den Dunnen, J. T. (2014). Efficient and sensitive identification and quantification of airborne pollen using nextgeneration DNA sequencing. Molecular Ecology Resources, 15 (1), 8-16. doi:10.1111/1755-0998.12288

Kratschmer, S., Petrović, B., Curto, M., Meimberg, H., \& Pachinger, B. (2020). Pollen availability for the Horned mason bee (

Osmia cornuta

) in regions of different land use and landscape structures.Ecological Entomology, 45 (3), 525-537. doi: $10.1111 /$ een. 12823

Kron, P., Loureiro, J., Castro, S., \& Čertner, M. (2021). Flow cytometric analysis of pollen and spores: An overview of applications and methodology. Cytometry Part A, 99 (4), 348-358. doi:10.1002/cyto.a.24330

Kurganskiy, A., Creer, S., Vere, N. d., Griffith, G. W., Osborne, N. J., Wheeler, B. W., . . . Skjøth, C. A. (2021). Predicting the severity of the grass pollen season and the effect of climate change in Northwest Europe. Science Advances, 7 (13), eabd7658. doi:10.1126/sciadv.abd7658

Kuzmina, M. L., Braukmann, T. W. A., Fazekas, A. J., Graham, S. W., Dewaard, S. L., Rodrigues, A., . . . Hebert, P. D. N. (2017). Using herbarium-derived DNAs to assemble a large-scale DNA barcode library for the vascular plants of Canada. Applications in Plant Sciences, 5 (12), apps.1700079. doi:10.3732/apps.1700079 
Lamb, P. D., Hunter, E., Pinnegar, J. K., Creer, S., Davies, R. G., \& Taylor, M. I. (2019). How quantitative is metabarcoding: A meta-analytical approach. Molecular Ecology, 28 (2), 420-430. doi:10.1111/mec.14920

Lang, D., Tang, M., Hu, J., \& Zhou, X. (2019). Genome-skimming provides accurate quantification for pollen mixtures. In Molecular Ecology Resources (Vol. 19, pp. 1433-1446): John Wiley \& Sons, Ltd (10.1111).

Lark, T. J., Meghan Salmon, J., \& Gibbs, H. K. (2015). Cropland expansion outpaces agricultural and biofuel policies in the United States. Environmental Research Letters, 10 (4), 044003. doi:10.1088/1748$9326 / 10 / 4 / 044003$

Lark, T. J., Spawn, S. A., Bougie, M., \& Gibbs, H. K. (2020). Cropland expansion in the United States produces marginal yields at high costs to wildlife. Nature Communications, 11 (1), 4295. doi:10.1038/s41467020-18045-Z

Lau, P., Bryant, V., Ellis, J. D., Huang, Z. Y., Sullivan, J., Schmehl, D. R., . . . Rangel, J. (2019). Seasonal variation of pollen collected by honey bees (Apis mellifera) in developed areas across four regions in the United States. PLoS one, 14 (6), e0217294. doi:10.1371/journal.pone.0217294

Leontidou, K., Vernesi, C., De Groeve, J., Cristofolini, F., Vokou, D., \& Cristofori, A. (2018). DNA metabarcoding of airborne pollen: new protocols for improved taxonomic identification of environmental samples. In Aerobiologia (Vol. 34, pp. 63-74): Springer Netherlands.

Leontidou, K., Vokou, D., Sandionigi, A., Bruno, A., Lazarina, M., De Groeve, J., . . . Cristofori, A. (2021). Plant biodiversity assessment through pollen DNA metabarcoding in Natura 2000 habitats (Italian Alps).Scientific Reports, 11, 18226.

Lewin, H. A., Robinson, G. E., Kress, W. J., Baker, W. J., Coddington, J., Crandall, K. A., . . . Zhang, G. (2018). Earth BioGenome Project: Sequencing life for the future of life. Proceedings of the National Academy of Sciences, 115 (17), 4325-4333. doi:10.1073/pnas.1720115115

Liu, S., Li, K., Jia, W., Stoof-Leichsenring, K. R., Liu, X., Cao, X., \& Herzschuh, U. (2021). Vegetation Reconstruction From Siberia and the Tibetan Plateau Using Modern Analogue TechniqueComparing Sedimentary (Ancient) DNA and Pollen Data. Frontiers in Ecology and Evolution, 9 , 668611. doi:10.3389/fevo.2021.668611

Loeza-Quintana, T., Abbott, C. L., Heath, D. D., Bernatchez, L., \& Hanner, R. H. (2020). Pathway to Increase Standards and Competency of eDNA Surveys (PISCeS) - Advancing collaboration and standardization efforts in the field of eDNA. Environmental DNA, 2 (3), 255-260. doi:10.1002/edn3.112

Lowenstein, D. M., Matteson, K. C., \& Minor, E. S. (2018). Evaluating the dependence of urban pollinators on ornamental, non-native, and 'weedy' floral resources. Urban Ecosystems, 22 (2), 293-302. doi:10.1007/s11252-018-0817-z

Lucas, A., Bodger, O., Brosi, B. J., Ford, C. R., Forman, D. W., Greig, C., . . . Vere, N. d. (2018). Floral resource partitioning by individuals within generalised hoverfly pollination networks revealed by DNA metabarcoding. In Scientific Reports (pp. 1-11): Springer US.

Lucas, A., Bodger, O., Brosi, B. J., Ford, C. R., Forman, D. W., Greig, C., . . . de Vere, N. (2018). Generalisation and specialisation in hoverfly (Syrphidae) grassland pollen transport networks revealed by DNA metabarcoding. In N. Sanders (Ed.), Journal of Animal Ecology .

Lucek, K., Galli, A., Gurten, S., Hohmann, N., Maccagni, A., Patsiou, T., \& Willi, Y. (2019). Metabarcoding of honey to assess differences in plant-pollinator interactions between urban and non-urban sites.Apidologie, 50 (3), 317-329. doi:10.1007/s13592-019-00646-3

MacGregor, C. J., Kitson, J. J. N., Fox, R., Hahn, C., Lunt, D. H., Pocock, M. J. O., \& Evans, D. M. (2019). Construction, validation, and application of nocturnal pollen transport networks in an agro- 
ecosystem: a comparison using light microscopy amd DNA metabarcoding.Ecological Entomology, 44 (1), 17-29. doi:10.1111/een.12674

Mander, L., \& Punyasena, S. W. (2014). On the taxonomic resolution of pollen and spore records of earth's vegetation. International Journal of Plant Sciences, 175 (8), 931-945. doi:10.1086/677680

Marcos, J. V., Nava, R., Cristobal, G., Redondo, R., Escalante-Ramirez, B., Bueno, G., . . . Rodriguez, T. (2015). Automated pollen identification using microscopic imaging and texture analysis.Micron, 68 , 36-46. doi:10.1016/j.micron.2014.09.002

Mata, V. A., Rebelo, H., Amorim, F., McCracken, G. F., Jarman, S., \& Beja, P. (2019). How much is enough? Effects of technical and biological replication on metabarcoding dietary analysis. In Molecular Ecology (Vol. 28, pp. 165-175).

Mathiasson, M. E., \& Rehan, S. M. (2020). Wild bee declines linked to plant-pollinator network changes and plant species introductions.Insect Conservation and Diversity, 13 (6), 595-605. doi:10.1111/icad.12429

MATSUKI, Y., ISAGI, Y., \& SUYAMA, Y. (2007). The determination of multiple microsatellite genotypes and DNA sequences from a single pollen grain. In Molecular Ecology Notes (Vol. 7, pp. 194-198).

Matsuki, Y., Tateno, R., Shibata, M., \& Isagi, Y. (2008). Pollination efficiencies of flower-visiting insects as determined by direct genetic analysis of pollen origin. American Journal of Botany, 95 (8), 925-930. doi:10.3732/ajb.0800036

McFrederick, Q. S., \& Rehan, S. M. (2016). Characterization of pollen and bacterial community composition in brood provisions of a small carpenter bee. In Molecular Ecology (Vol. 25, pp. 2302-2311).

Milla, E., Bovill, J., Schmidt-Lebuhn, A. N., \& Encinas-Viso, F. (in press). Monitoring of honey bee floral resources with pollen DNA metabarcoding as a complementary tool to vegetation surveys. Ecological Solutions and Evidence, in press .

Moorhouse-Gann, R. J., Dunn, J. C., de Vere, N., Goder, M., Cole, N., Hipperson, H., \& Symondson, W. O. C. (2018). New universal ITS2 primers for high-resolution herbivory analyses using DNA metabarcoding in both tropical and temperate zones. In Scientific Reports (Vol. 8, pp. 8542).

Muthreich, F., Zimmermann, B., Birks, H. J. B., Vila-Vicosa, C. M., \& Seddon, A. W. R. (2020). Chemical variations in Quercus pollen as a tool for taxonomic identification: Implications for long-term ecological and biogeographical research. Journal of Biogeography, 47 (6), 1298-1309. doi:10.1111/jbi.13817

Nakazawa, F., Uetake, J., Suyama, Y., Kaneko, R., Takeuchi, N., Fujita, K., . . . Kanda, H. (2013). DNA analysis for section identification of individual Pinus pollen grains from Belukha glacier, Altai Mountains, Russia. Environmental Research Letters, 8 , 014032. doi:10.1088/1748-9326/8/1/014032

Nichols, R. V., Vollmers, C., Newsom, L. A., Wang, Y., Heintzman, P. D., Leighton, M., . . . Shapiro, B. (2018). Minimizing polymerase biases in metabarcoding. In Molecular Ecology Resources : Wiley/Blackwell (10.1111).

Niemeyer, B., Epp, L. S., Stoof-Leichsenring, K. R., Pestryakova, L. A., \& Herzschuh, U. (2017). A comparison of sedimentary DNA and pollen from lake sediments in recording vegetation composition at the Siberian treeline. In Molecular Ecology Resources (Vol. 17, pp. e46-e62).

Nurnberger, F., Keller, A., Hartel, S., \& Steffan-Dewenter, I. (2019). Honey bee waggle dance communication increases diversity of pollen diets in intensively managed agricultural landscapes. Molecular Ecology, 28 (15), 3602-3611. doi:10.1111/mec.15156

O'Donnell, J. L., Kelly, R. P., Lowell, N. C., \& Port, J. A. (2016). Indexed PCR Primers Induce Template-Specific Bias in Large-Scale DNA Sequencing Studies. PLoS one, 11 (3), e0148698. doi:10.1371/journal.pone.0148698 
Olsson, O., Karlsson, M., Persson, A. S., Smith, H. G., Varadarajan, V., Yourstone, J., . . . Freckleton, R. (2021). Efficient, automated and robust pollen analysis using deep learning. Methods in Ecology and Evolution, 12 (5), 850-862. doi:10.1111/2041-210x.13575

Otto, C. R. V., Roth, C. L., Carlson, B. L., \& Smart, M. D. (2016). Land-use change reduces habitat suitability for supporting managed honey bee colonies in the Northern Great Plains. Proceedings of the National Academy of Sciences, 113 (37), 10430-10435. doi:10.1073/pnas.1603481113

Paffetti, D., Vettori, C., Caramelli, D., Vernesi, C., Lari, M., Paganelli, A., . . . Giannini, R. (2007). Unexpected presence of Fagus orientalis complex in Italy as inferred from 45,000-year-old DNA pollen samples from Venice lagoon. BMC Evolutionary Biology, 7 (2), S6. doi:10.1186/1471-2148-7-S2-S6

Parducci, L., Alsos, I. G., Unneberg, P., Pedersen, M. W., Han, L., Lammers, Y., . . . Wohlfarth, B. (2019). Shotgun Environmental DNA, Pollen, and Macrofossil Analysis of Lateglacial Lake Sediments From Southern Sweden. In Frontiers in Ecology and Evolution (Vol. 7, pp. 189): Frontiers.

Parducci, L., Bennett, K. D., Ficetola, G. F., Alsos, I. G., Suyama, Y., Wood, J. R., \& Pedersen, M. W. (2017). Ancient plant DNA in lake sediments. In New Phytologist (Vol. 214, pp. 924-942).

Parducci, L., Nota, K., \& Wood, J. R. (2019). Reconstructing Past Vegetation Communities Using Ancient DNA from Lake Sediments. In C. Lindqvist \& O. P. Rajora (Eds.), Paleogenomics: Genome-Scale Analysis of Ancient DNA (pp. 163-187). Cham: Springer International Publishing.

Parducci, L., Suyama, Y., Lascoux, M., \& Bennett, K. D. (2005). Ancient DNA from pollen: a genetic record of population history in Scots pine. In Molecular Ecology (Vol. 14, pp. 2873-2882).

Parsons, K. M., Everett, M., Dahlheim, M., \& Park, L. (2018). Water, water everywhere: environmental DNA can unlock population structure in elusive marine species. Royal Society Open Science, 5 (8), 180537. doi:10.1098/rsos.180537

Pawluczyk, M., Weiss, J., Links, M. G., Egana Aranguren, M., Wilkinson, M. D., \& Egea-Cortines, M. (2015). Quantitative evaluation of bias in PCR amplification and next-generation sequencing derived from metabarcoding samples. Analytical and Bioanalytical Chemistry, 407 (7), 1841-1848. doi:10.1007/s00216014-8435-y

Pedersen, M. W., De Sanctis, B., Saremi, N. F., Sikora, M., Puckett, E. E., Gu, Z., . . . Willerslev, E. (2021). Environmental genomics of Late Pleistocene black bears and giant short-faced bears. Current Biology, 31 (12), 2728-2736.e2728. doi:10.1016/j.cub.2021.04.027

Peel, N., Dicks, L. V., Clark, M. D., Heavens, D., Percival-Alwyn, L., Cooper, C., . . . Yu, D. W. (2019). Semi-quantitative characterisation of mixed pollen samples using MinION sequencing and Reverse Metagenomics (RevMet). Methods in Ecology and Evolution, 10 (10), 1690-1701. doi:10.1111/2041-210X.13265

Pereira, S. G., Guedes, A., Abreu, I., \& Ribeiro, H. (2021). Testing the Raman parameters of pollen spectra in automatic identification.Aerobiologia, 37 (1), 15-28. doi:10.1007/s10453-020-09669-1

Peters, M. K., Hemp, A., Appelhans, T., Becker, J. N., Behler, C., Classen, A., . . . Steffan-Dewenter, I. (2019). Climate-land-use interactions shape tropical mountain biodiversity and ecosystem functions. Nature, 568 (7750), 88-92. doi:10.1038/s41586-019-1048-z

Petersen, G., Johansen, B., \& Seberg, O. (1996). PCR and sequencing from a single pollen grain. In Plant Molecular Biology (Vol. 31, pp. 189-191).

Piko, J., Keller, A., Geppert, C., Batary, P., Tscharntke, T., Westphal, C., \& Hass, A. L. (2021). Effects of three flower field types on bumblebees and their pollen diets. Basic and Applied Ecology, 52 , 95-108. doi:10.1016/j.baae.2021.02.005

Pimm, S. L., \& Joppa, L. N. (2015). How many plant species are there, where are they, and what rate are they going extinct? Annals of the Missouri Botanical Garden, 100 (170-176). 
Pinol, J., Senar, M. A., \& Symondson, W. O. C. (2019). The choice of universal primers and the characteristics of the species mixture determine when DNA metabarcoding can be quantitative. In Molecular Ecology (Vol. 28, pp. 407-419): Wiley/Blackwell (10.1111).

Polling, M., Li, C., Cao, L., Verbeek, F., de Weger, L. A., Belmonte, J., . . . Gravendeel, B. (2021). Neural networks for increased accuracy of allergenic pollen monitoring. Scientific Reports, 11 (1), 11357. doi:10.1038/s41598-021-90433-x

Polling, M., Sin, M., de Weger, L. A., Speksnijder, A. G. C. L., Koenders, M. J. F., de Boer, H., \& Gravendeel, B. (2022). DNA metabarcoding using nrITS2 provides highly qualitative and quantitative results for airborne pollen monitoring. Science of The Total Environment, 806 , 150468. doi:https://doi.org/10.1016/j.scitotenv.2021.150468

Pompanon, F., Deagle, B. E., Symondson, W. O., Brown, D. S., Jarman, S. N., \& Taberlet, P. (2012). Who is eating what: diet assessment using next generation sequencing. Molecular Ecology, 21 (8), 1931-1950. doi:10.1111/j.1365-294X.2011.05403.x

Popic, T. J., Wardle, G. M., \& Davila, Y. C. (2013). Flower-visitor networks only partially predict the function of pollen transport by bees. Austral Ecology, 38 (1), 76-86. doi:10.1111/j.1442-9993.2012.02377.x

Pornon, A., Andalo, C., Burrus, M., \& Escaravage, N. (2017). DNA metabarcoding data unveils invisible pollination networks. InScientific Reports (Vol. 7, pp. 16828).

Pornon, A., Escaravage, N., Burrus, M., Holota, H., Khimoun, A., Mariette, J., . . . Andalo, C. (2016). Using metabarcoding to reveal and quantify plant-pollinator interactions. In Scientific Reports(Vol. 6, pp. 27282).

Portman, Z. M., Tepedino, V. J., Tripodi, A. D., Szalanski, A. L., \& Durham, S. L. (2018). Local extinction of a rare plant pollinator in Southern Utah (USA) associated with invasion by Africanized honey bees.Biological Invasions, 20 (3), 593-606. doi:10.1007/s10530-017-1559-1

Potter, C., de Vere, N., Jones, L. E., Ford, C. R., Hegarty, M. J., Hodder, K. H., . . . Franklin, E. L. (2019). Pollen metabarcoding reveals broad and species-specific resource use by urban bees.PeerJ, 7 , e5999. doi:10.7717/peerj.5999

Potts, S. G., Biesmeijer, J. C., Kremen, C., Neumann, P., Schweiger, O., \& Kunin, W. E. (2010). Global pollinator declines: trends, impacts and drivers. Trends Ecol Evol, 25 (6), 345-353. doi:10.1016/j.tree.2010.01.007

Pyšek, P., Hulme, P. E., Simberloff, D., Bacher, S., Blackburn, T. M., Carlton, J. T., . . . Richardson, D. M. (2020). Scientists' warning on invasive alien species. Biological Reviews, 95 (6), 1511-1534. doi:https://doi.org/10.1111/brv.12627

Quaresma, A., Brodschneider, R., Gratzer, K., Gray, A., Keller, A., Kilpinen, O., . . . Pinto, M. A. (2021). Preservation methods of honey bee-collected pollen are not a source of bias in ITS2 metabarcoding.Environmental Monitoring and Assessment, 193 (12), 785. doi:10.1007/s10661-021-09563-4

Reilly, J. R., Artz, D. R., Biddinger, D., Bobiwash, K., Boyle, N. K., Brittain, C., . . . Winfree, R. (2020). Crop production in the USA is frequently limited by a lack of pollinators. Proceedings of the Royal Society B: Biological Sciences, 287 (1931), 20200922. doi:10.1098/rspb.2020.0922

Revilla, T. A., Encinas-Viso, F., \& Loreau, M. (2015). Robustness of mutualistic networks under phenological change and habitat destruction.Oikos, 124, 22-32. doi:10.1111/OIK.01532

Richardson, R. T., Curtis, H. R., Matcham, E. G., Hua Lin, C., Suresh, S., Sponsler, D. B., . . . Johnson, R. M. (2018). Quantitative multi-locus metabarcoding and waggle dance interpretation reveal honey bee spring foraging patterns in Midwest agroecosystems. Molecular Ecology, 28 (3), 686-697. doi:10.1111/mec.14975

Richardson, R. T., Eaton, T. D., Lin, C. H., Cherry, G., Johnson, R. M., \& Sponsler, D. B. (2021). Application of plant metabarcoding to identify diverse honeybee pollen forage along an urban-agricultural gradient. 
In Molecular Ecology (Vol. 30, pp. 310-323).

Richardson, R. T., Lin, C.-H., Quijia, J. O., Riusech, N. S., Goodell, K., \& Johnson, R. M. (2015). RankBased Characterization of Pollen Assemblages Collected by Honey Bees Using a Multi-Locus Metabarcoding Approach. In Applications in Plant Sciences (Vol. 3, pp. 1500043).

Richardson, R. T., Sponsler, D. B., McMinn-Sauder, H., \& Johnson, R. M. (2020). MetaCurator: A hidden Markov model-based toolkit for extracting and curating sequences from taxonomically-informative genetic markers. Methods in Ecology and Evolution, 11 (1), 181-186. doi:10.1111/2041-210x.13314

Rognes, T., Flouri, T., Nichols, B., Quince, C., \& Mahe, F. (2016). VSEARCH: a versatile open source tool for metagenomics. PeerJ, 4, e2584. doi:10.7717/peerj.2584

Rowney, F. M., Brennan, G. L., Skjoth, C. A., Griffith, G. W., McInnes, R. N., Clewlow, Y., . . . Creer, S. (2021). Environmental DNA reveals links between abundance and composition of airborne grass pollen and respiratory health. Current Biology, 31 (9), 1995-2003 e1994. doi:10.1016/j.cub.2021.02.019

Samuelson, A. E., Gill, R. J., \& Leadbeater, E. (2020). Urbanisation is associated with reduced Nosema sp. infection, higher colony strength and higher richness of foraged pollen in honeybees. Apidologie, 51 (5), 746-762. doi:10.1007/s13592-020-00758-1

Schmidt, B. R., Kéry, M., Ursenbacher, S., Hyman, O. J., Collins, J. P., \& Yoccoz, N. (2013). Site occupancy models in the analysis of environmental DNA presence/absence surveys: a case study of an emerging amphibian pathogen. Methods in Ecology and Evolution, 4 (7), 646-653. doi:10.1111/2041-210x.12052

Sepulveda, A. J., Nelson, N. M., Jerde, C. L., \& Luikart, G. (2020). Are Environmental DNA Methods Ready for Aquatic Invasive Species Management? Trends Ecol Evol, 35 (8), 668-678. doi:10.1016/j.tree.2020.03.011

Sevillano, V., Holt, K., \& Aznarte, J. L. (2020). Precise automatic classification of 46 different pollen types with convolutional neural networks. PLoS one, 15 (6), e0229751. doi:10.1371/journal.pone.0229751

Sickel, W., Ankenbrand, M. J., Grimmer, G., Holzschuh, A., Härtel, S., Lanzen, J., . . Keller, A. (2015). Increased efficiency in identifying mixed pollen samples by meta-barcoding with a dual-indexing approach. In BMC Ecology (Vol. 15, pp. 20).

Sigsgaard, E. E., Nielsen, I. B., Bach, S. S., Lorenzen, E. D., Robinson, D. P., Knudsen, S. W., . . Thomsen, P. F. (2016). Population characteristics of a large whale shark aggregation inferred from seawater environmental DNA. Nature Ecology $\&$ Evolution, 1 (1), 0004. doi:10.1038/s41559-016-0004

Simanonok, M. P., Otto, C. R. V., Cornman, R. S., Iwanowicz, D. D., Strange, J. P., \& Smith, T. A. (2021). A century of pollen foraging by the endangered rusty patched bumble bee (Bombus affinis): inferences from molecular sequencing of museum specimens. Biodiversity and Conservation, 30 , 123-137. doi:10.1007/s10531-020-02081-8

Smith, C., Weinman, L., Gibbs, J., \& Winfree, R. (2019). Specialist foragers in forest bee communities are small, social or emerge early. Journal of Animal Ecology, 88 (8), 1158-1167. doi:10.1111/1365-2656.13003

Smith, M. R., Singh, G. M., Mozaffarian, D., \& Myers, S. S. (2015). Effects of decreases of animal pollinators on human nutrition and global health: a modelling analysis. The Lancet, 386 (10007), 1964-1972. doi:10.1016/s0140-6736(15)61085-6

Song, X.-P., Hansen, M. C., Stehman, S. V., Potapov, P. V., Tyukavina, A., Vermote, E. F., \& Townshend, J. R. (2018). Global land change from 1982 to 2016. Nature, 560 (7720), 639-643. doi:10.1038/s41586-018-0411-9

Sponsler, D. B., Shump, D., Richardson, R. T., \& Grozinger, C. M. (2020). Characterizing the floral resources of a North American metropolis using a honey bee foraging assay. Ecosphere, 11 (4), e03102.

Stillman, E. C., \& Flenley, J. R. (1996). The needs and prospects for automation in palynology. Quaternary Science Reviews, 15 (1), 1-5. doi:10.1016/0277-3791(95)00076-3 
Suanno, C., Aloisi, I., Fernández-González, D., \& Del Duca, S. (2021). Monitoring techniques for pollen allergy risk assessment.Environmental Research, 197 , 111109. doi:https://doi.org/10.1016/j.envres.2021.111109

Suchan, T., Talavera, G., Saez, L., Ronikier, M., \& Vila, R. (2019). Pollen metabarcoding as a tool for tracking long-distance insect migrations. Molecular Ecology Resources, 19 (1), 149-162. doi:10.1111/1755-0998.12948

Suyama, Y. (2011). Procedure for Single-Pollen Genotyping. In Y. Isagi \& Y. Suyama (Eds.), Single-Pollen Genotyping (pp. 7-15). Tokyo: Springer Japan.

Suyama, Y., Kawamuro, K., Kinoshita, I., Yoshimura, K., Tsumura, Y., \& Takahara, H. (1996). DNA sequence from a fossil pollen of $<\mathrm{i}>$ Abies $</ \mathrm{i}>$ spp. from Pleistocene peat. Genes 83 Genetic Systems, 71 (3), 145-149. doi:10.1266/ggs.71.145

Swenson, S. J., \& Gemeinholzer, B. (2021). Testing the effect of pollen exine rupture on metabarcoding with Illumina sequencing. In B. Heinze (Ed.), PLoS one (Vol. 16, pp. e0245611).

Taberlet, P., Coissac, E., Pompanon, F., Brochmann, C., \& Willerslev, E. (2012). Towards next-generation biodiversity assessment using DNA metabarcoding. In Molecular Ecology (Vol. 21, pp. 2045-2050).

Tanaka, K., Nozaki, A., Nakadai, H., Shiwa, Y., \& Shimizu-Kadota, M. (2020). Using pollen DNA metabarcoding to profile nectar sources of urban beekeeping in Kōtō-ku, Tokyo. In.

Threlfall, C. G., Walker, K., Williams, N. S. G., Hahs, A. K., Mata, L., Stork, N., \& Livesley, S. J. (2015). The conservation value of urban green space habitats for Australian native bee communities.Biological Conservation, 187 , 240-248. doi:10.1016/j.biocon.2015.05.003

Tommasi, N., Ferrari, A., Labra, M., Galimberti, A., \& Biella, P. (2021). Harnessing the Power of Metabarcoding in the Ecological Interpretation of Plant-Pollinator DNA Data: Strategies and Consequences of Filtering Approaches. Diversity, 13 (9), 437.

Tremblay, É. D., Duceppe, M.-O., Thurston, G. B., Gagnon, M.-C., Côté, M.-J., \& Bilodeau, G. J. (2019). High-resolution biomonitoring of plant pathogens and plant species using metabarcoding of pollen pellet contents collected from a honey bee hive. In Environmental DNA : John Wiley \& Sons, Ltd.

Trinkl, M., Kaluza, B. F., Wallace, H., Heard, T. A., Keller, A., \& Leonhardt, S. D. (2020). Floral Species Richness Correlates with Changes in the Nutritional Quality of Larval Diets in a Stingless Bee.Insects, 11 (2). doi:10.3390/insects11020125

Tur, C., Vigalondo, B., Trojelsgaard, K., Olesen, J. M., \& Traveset, A. (2014). Downscaling pollen-transport networks to the level of individuals. Journal of Animal Ecology, 83 (1), 306-317. doi:10.1111/1365-2656.12130

Turo, K. J., \& Gardiner, M. M. (2019). From potential to practical: conserving bees in urban public green spaces. Frontiers in Ecology and the Environment, 17 (3), 167-175. doi:10.1002/fee.2015

Uetake, J., Tobo, Y., Kobayashi, S., Tanaka, K., Watanabe, S., DeMott, P. J., \& Kreidenweis, S. M. (2021). Visualization of the seasonal shift of a variety of airborne pollens in western Tokyo. In Science of The Total Environment (Vol. 788, pp. 147623).

Vannette, R. L. (2020). The Floral Microbiome: Plant, Pollinator, and Microbial Perspectives. Annual Review of Ecology, Evolution, and Systematics, 51 (1), 363-386. doi:10.1146/annurev-ecolsys-011720-013401

Vaudo, A. D., Biddinger, D. J., Sickel, W., Keller, A., \& López-Uribe, M. M. (2020). Introduced bees (Osmia cornifrons ) collect pollen from both coevolved and novel host-plant species within their family-level phylogenetic preferences. Royal Society Open Science, 7 , 200225. doi:10.1098/rsos.200225

10.6084/m9.figshare.c

Voulgari-Kokota, A., Grimmer, G., Steffan-Dewenter, I., \& Keller, A. (2018). Bacterial community structure and succession in nests of two megachilid bee genera. FEMS Microbiology Ecology, 95 (1). doi:10.1093/femsec/fiy218 
Voulgari-Kokota, A., Steffan-Dewenter, I., \& Keller, A. (2020). Susceptibility of Red Mason Bee Larvae to Bacterial Threats Due to Microbiome Exchange with Imported Pollen Provisions. Insects, 11 (6), 373. doi:10.3390/insects11060373

Vuong, H. Q., \& McFrederick, Q. S. (2019). Comparative Genomics of Wild Bee and Flower Isolated Lactobacillus Reveals Potential Adaptation to the Bee Host. Genome Biology and Evolution, 11 (8), 2151-2161. doi:10.1093/gbe/evz136

Wagemaker, C. A. M., Mommer, L., Visser, E. J. W., Weigelt, A., van Gurp, T. P., Postuma, M., . . . de Kroon, H. (2021). msGBS: A new high-throughput approach to quantify the relative species abundance in root samples of multispecies plant communities. Mol Ecol Resour, 21 (4), 1021-1036. doi:10.1111/17550998.13278

Wenzel, A., Grass, I., Belavadi, V. V., \& Tscharntke, T. (2020). How urbanization is driving pollinator diversity and pollination - A systematic review. Biological Conservation, 241 , 108321. doi:10.1016/j.biocon.2019.108321

Wilmshurst, J. M., Moar, N. T., Wood, J. R., Bellingham, P. J., Findlater, A. M., Robinson, J. J., \& Stone, C. (2014). Use of pollen and ancient DNA as conservation baselines for offshore islands in New Zealand. Conservation Biology, 28 (1), 202-212. doi:10.1111/cobi.12150

Wilson, R. S., Keller, A., Shapcott, A., Leonhardt, S. D., Sickel, W., Hardwick, J. L., . . Wallace, H. M. (2021). Many small rather than few large sources identified in long-term bee pollen diets in agroecosystems. In Agriculture, Ecosystems 83 Environment (Vol. 310, pp. 107296).

Yilmaz, P., Kottmann, R., Field, D., Knight, R., Cole, J. R., Amaral-Zettler, L., . . Glockner, F. O. (2011). Minimum information about a marker gene sequence (MIMARKS) and minimum information about any $(\mathrm{x})$ sequence (MIxS) specifications. Nature Biotechnology, 29 (5), 415-420. doi:10.1038/nbt.1823

Zemenick, A. T., Vannette, R. L., \& Rosenheim, J. A. (2021). Linked networks reveal dual roles of insect dispersal and species sorting for bacterial communities in flowers. Oikos, 130 , 697-707. doi:10.1101/847376

Zhang, J., Kobert, K., Flouri, T., \& Stamatakis, A. (2014). PEAR: a fast and accurate Illumina Paired-End reAd mergeR. Bioinformatics, 30 (5), 614-620. doi:10.1093/bioinformatics/btt593

Zhao, Y. H., Lázaro, A., Ren, Z. X., Zhou, W., Li, H. D., Tao, Z. B., . . Wang, H. (2018). The topological differences between visitation and pollen transport networks: a comparison in species rich communities of the Himalaya-Hengduan Mountains. Oikos, 128 (4), 551-562. doi:10.1111/oik.05262

Zimmermann, B. (2018). Chemical characterization and identification of Pinaceae pollen by infrared microspectroscopy. Planta, 247 (1), 171-180. doi:10.1007/s00425-017-2774-9

Data Accessibility and Benefit Sharing

The data that supports the findings of this study are available in the supplementary material of this article. No biological samples were collected or analyzed in this article. 
A

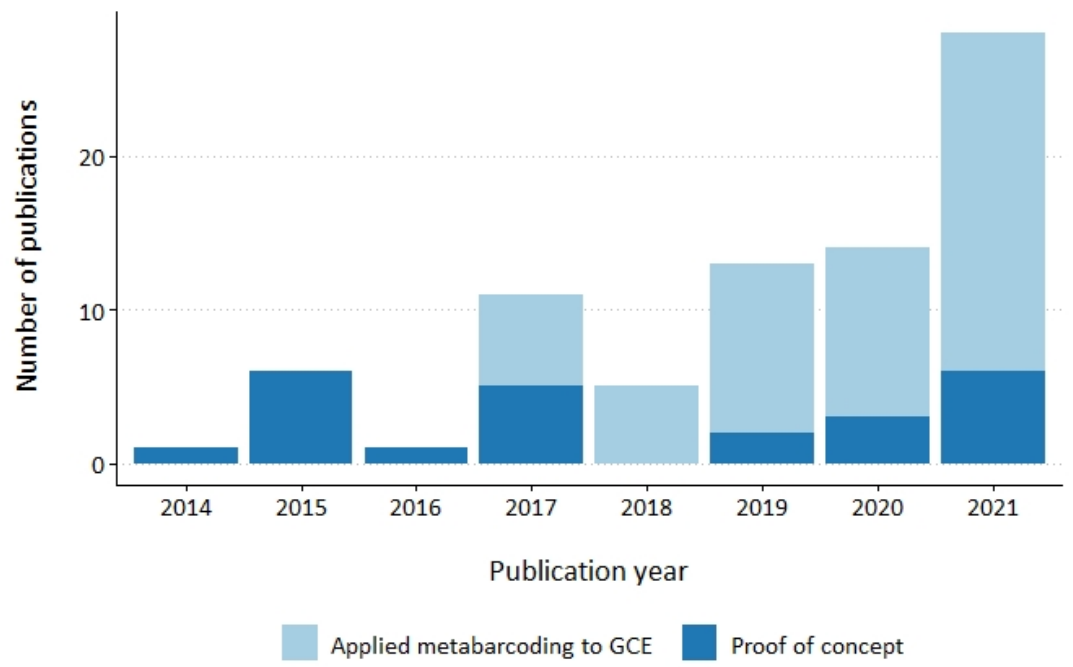

B

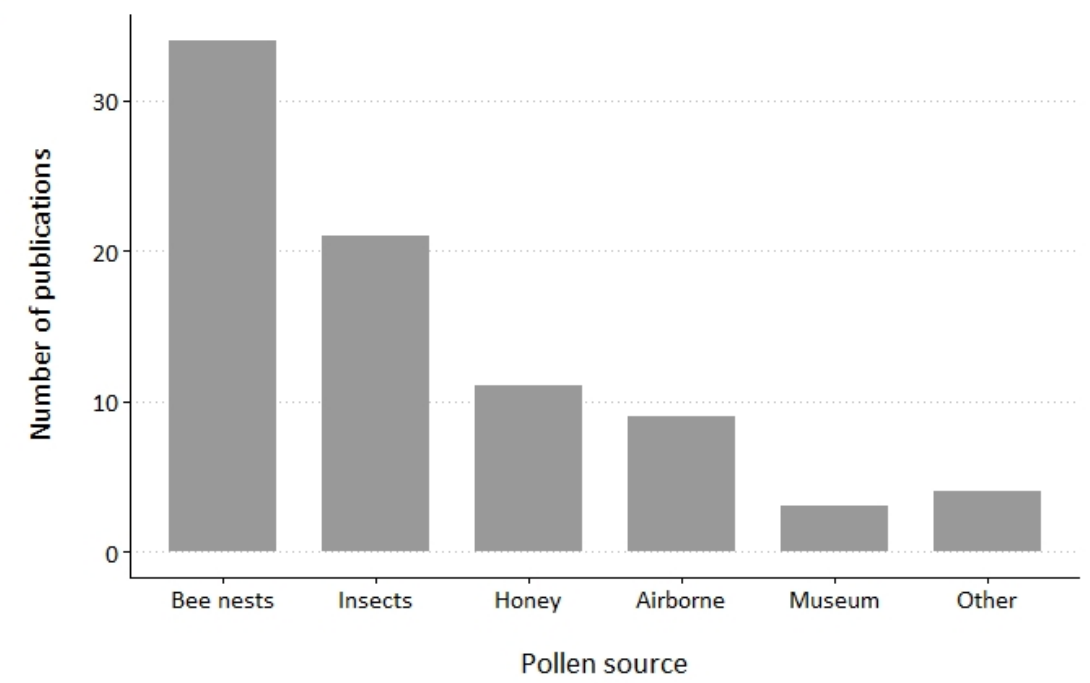

Figure 1. (A) Studies using pollen DNA metabarcoding or related methods to demonstrate proof-of-concept or applied questions in global change ecology $(\mathrm{GCE})(\mathrm{n}=80)$. (B) Studies characterized by pollen source $(\mathrm{n}=80)$. Bee nests included pollen collected from honeybee hives with a pollen trap $(\mathrm{n}=20)$ and pollen provisions taken from solitary cavity nesting bees $(\mathrm{n}=15)$. Insects were predominately net or hand collected foraging bees $(n=16)$ but some flies (Syrphidae) $(n=7)$ and moths $(n=3)$ were also focal subjects. Pollen sourced from bats $(\mathrm{n}=1)$, soil $(\mathrm{n}=1)$, a glacial core $(\mathrm{n}=1)$, and a commercially sourced pollen diet supplement $(\mathrm{n}=1)$ were categorized as Other. 


\section{Obtain pollen}

a

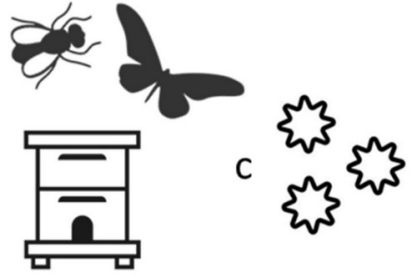

3. Isolate/sequence DNA

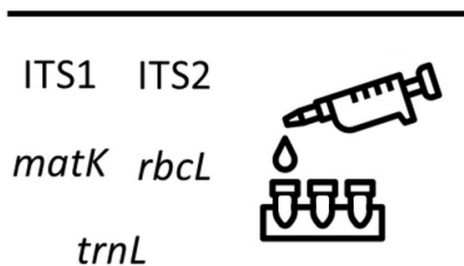

\section{Create reference database}

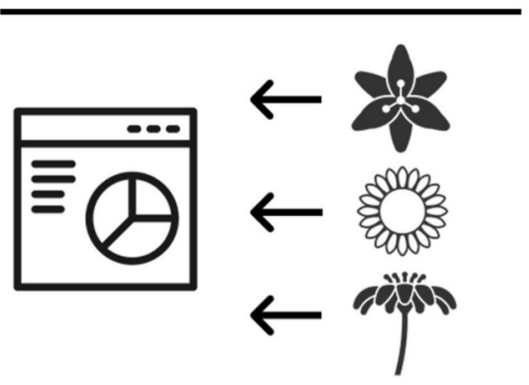

4. Bioinformatics

Figure 2: Graphical depiction of the workflow of a study involving DNA-based pollen identification. Prior to starting the study, decisions need to be made on: (1) the method to obtain pollen from the environment, e.g., from (a) a pollinator's body, (b) nest, or (c) the air; (2) the gene regions and methods to create the reference database; (3) the appropriate method for the isolation and sequencing of DNA; and (4) the bioinformatics methods to be used. These decisions will depend on the questions, the study system, the availability of existing reference sequences, and the funding. 